\title{
Educational Reform: A Case Study of Teachers' Attitudes, Perceptions, and Engagement Throughout Curricular Reform
}

G. Colin Castelow

Follow this and additional works at: http://digitalcommons.cedarville.edu/education_theses

Part of the Curriculum and Instruction Commons, Educational Leadership Commons, and the Elementary and Middle and Secondary Education Administration Commons

\section{Recommended Citation}

Castelow, G. Colin, "Educational Reform: A Case Study of Teachers' Attitudes, Perceptions, and Engagement Throughout Curricular Reform" (2014). Master of Education Research Theses. 73.

http://digitalcommons.cedarville.edu/education_theses/73 
Educational Reform: A Case Study of Teachers' Attitudes, Perceptions, and Engagement Throughout Curricular Reform

A thesis submitted in partial fulfillment

for the requirements of the degree

Masters of Education

By

G. Colin Castelow

B.A. in Speech Education, Cedarville University, 1997

2014

CEDARVILLE UNIVERSITY 


\begin{abstract}
This applied research project uses a mixed method approach to analyze curricular reform at a private Christian school in Chesapeake, Virginia. The study aimed to answer two questions regarding curricular reform at the school. Are the teachers seeking to improve the curriculum to which they have been entrusted? Have their attitudes and perceptions regarding the change in template evolved over time? Using the Concerns-Based Adoption Model, two separate surveys were coded based on the model's Stages of Concern and Levels of Use. An initial teacher survey provided data and open-ended responses on the participant's willingness to implement the reformed device. The follow-up survey provided data on the participants' perceived evolution of attitude relative to the reform measure. Furthermore the follow-up survey provided open-ended responses by which the participants' engagement with the unit plan was evaluated. The analysis of both data and participants' statements resulted in confirmation of principles previously establish in published literature regarding educational reform: including the principles of contradiction, resistance, and perspective. Thus the findings suggest that the administration target select areas of the unit plan in order to clarify teacher misconceptions and to further improve teacher engagement.
\end{abstract}




\section{TABLE OF CONTENTS}

\section{Page}

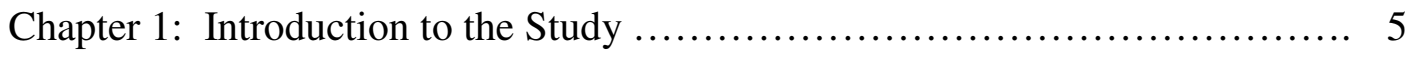

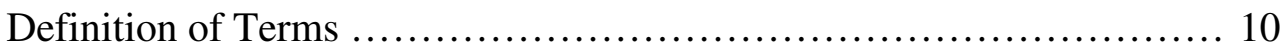

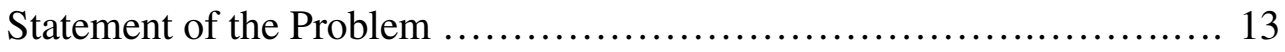

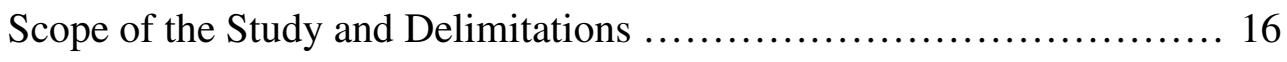

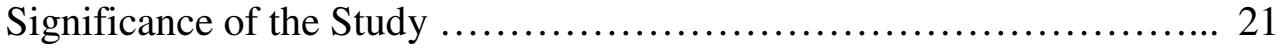

Methods of Procedure ....................................... 22

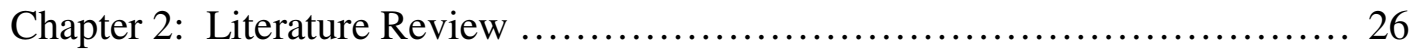

The Philosophies Behind Reform ................................. 28

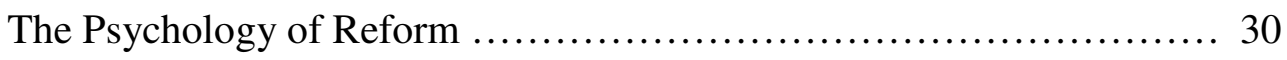

The Leadership's of Reform ................................... 32

The Business of Reform ......................................... 35

The Principal's Role in Reform ................................ 41

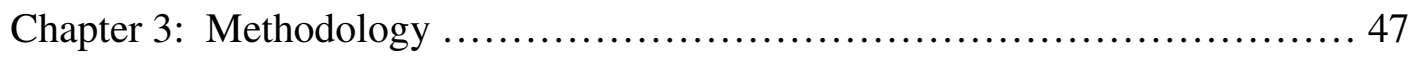

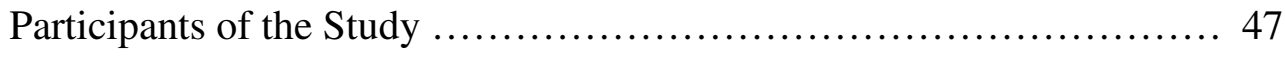

Research Procedure ............................................. 49

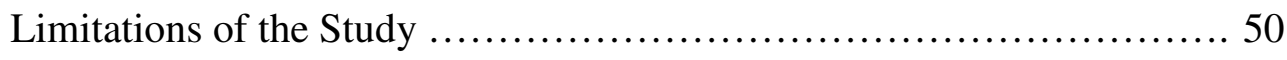

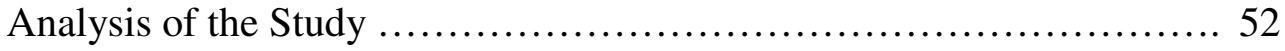

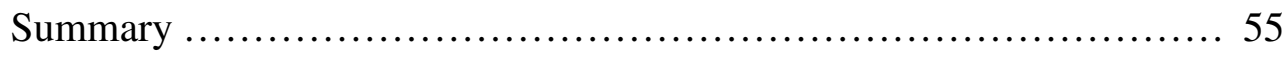

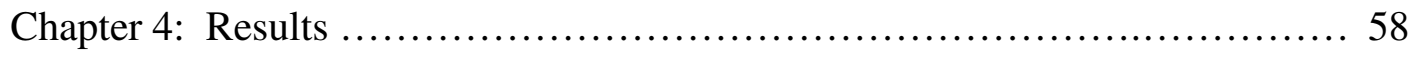

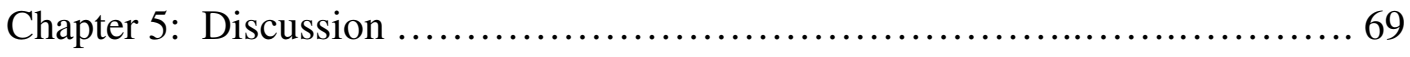


Recommendations ............................................. 76

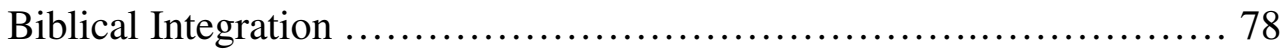

Suggestions for Further Research ................................ 81

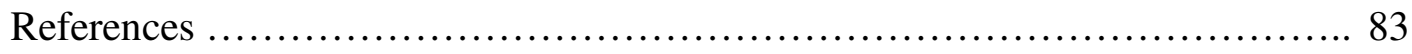

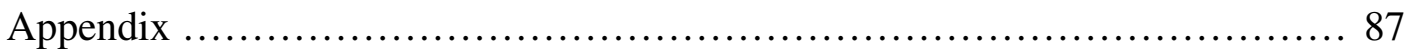




\section{Chapter 1: Introduction}

\section{Introduction to the Study}

In the now classic film, Dead Poet's Society, the start of a new school year begins with an awkward introduction between teacher and students. Following a standard reading of the literature textbook's introduction, Mr. Keating, a newly employed teacher of the renowned institution, turns to the class and pronounces the introductory comments within the book to be "excrement." The dismissal of the well-established, curricular wisdom incites confusion, shock, and curiosity throughout the room. Student reactions amplify as the instruction given by Mr. Keating turns from a denouncement of the accepted academia to a directive of destruction wherein each student must remove the opening preface of the textbook. The directive soon gives way to the sound of a classroom gleefully dismantling a revered literature curriculum. Mr. Keating cheers his emboldened students by declaring "This is a battle, a war. And the casualties could be your hearts and souls" (Haft, 1989).

While this scene from the classic film Dead Poets Society depicts a centralized theme of shedding the mental shackles which inhibit free thinking, such is accomplished through a lesser subplot of educational reform. Within the context of the film, Mr. Keating embodies the reformer whose approach to the stagnant curricula creates tension between administration and the teacher - inevitable impacting the lives of his students. Reformation inescapably brings conflict between the reformer and conformist. In this researcher's opinion, the impact of any given educational reform reaches well beyond the principal players within the debate. Ultimately, reform extends into the lives of the students within the classroom, the families of those involved in the debate, and the community - whether local or global - at large. 
The film Dead Poets Society does not stand alone in the usage of observable school reforms. Several other filmmakers have taken advantage of the conflict found in contentious change and have offered audiences moving tales of reform's impact in society. Lean On Me provides audiences with an inspiring tale of one administrator whose tough love approach to discipline reforms a failing and crime-ridden local school. With a stirring musical score, $M r$. Holland's Opus demonstrates the personal challenges and changes one individual faces throughout the course of his 30-year career. Set within the gritty realities of the 1990's, Dangerous Minds illustrates that determination and dedication for awakening the potential in young learners can produce reform within the lives of students who were once written off as hopeless. Such film depictions of reformation - some fictional, some loosely based on true stories - ultimately inspire both educators and non-educators alike.

However the inspiration to change and the actions of reform implementation rarely align in today's diverse culture. Almost hauntingly, James R. Gress's (1976) reflections regarding curriculum reform ring as true today as the day when he penned that

an essential difference ... between change in 1976 and change in 1930s or in 1776 would seem to be the Tofflerian vertigo brought on by the increasing acceleration of change ... [which] confuses the predictability of human experience and mortally threatens the stability of our very existence (p. 99).

In truth, reform appears to be a constant factor within formalized education even from the earliest of days the current American system. During the first half of the nineteenth century, reformers pushed for the common school; during the latter half of the same century, reformers sought to standardize the curricular objectives; advance another fifty years to find reformers 
diversifying the curricular offerings (Gress, 1976, p. 99-100). Thus, history reveals a cycle of reform wherein reform initiatives of the past lead to reform initiatives in the present. Inevitably, each cycle of reform influences reform initiatives of the future - in some cases negating the reform efforts of the previous reformers. Lee and Ready (2009) postulate that such a cycle of reform is the result of two contradictory philosophies competing within the education system. One philosophy is grounded in the ideal of equality of educational programming, and the other is grounded in the ideal of individual choice. Thus, progresses made by reformers from times past continue to speak within contemporary educational debates. Unfortunately, the splintering of the original, underlying philosophies into diminutive subset-debates further exacerbates attempts at stability.

Yet educators seem to accept what they must and change what they can. In other words the idealism which initially sparked the efforts of change often is compromised by the variety of voices. Voices, some of which may or may not agree, hold the responsibility of implementing the reform measures. Consider the example set by the School District of Philadelphia which in 2006 surrendered control of one of its failing public schools to Mastery Charter Schools which produced measurable reform within a span of a three years (Cruz, 2010). Others reject the feasibility of such sweeping changes and relegate their reforms to isolated aspects within the system. Whether the aspect in focus be altering the school calendar (Hamilton, Johnston, Marshall, \& Shields, 2006), expanding the responsibilities of the teaching staff (Sawchuk, 2011), or merging methodological approaches in the twenty-first century (Ullman, 2012), the current education system does not lack for acute reformation attempts. 
Still others within the field of education simply participate in the debate through philosophical writings. Morrison and Sams (2011) offer such participation via their "Letter from the Editorial Board." Rather than praising or denouncing actions specific to current educational reforms, the two men postulate that reform ultimately restricts all parties involved in the process of education. Such restrictions are due to a misguided effort of replicating (in mass) narrow perspectives of theoretical, antidotal, or observably defined "good" teaching practices. Furthermore, the restricted focal point overlooks the art of human interaction. Extending beyond the quantifiable aspects of teaching, the interdependence of humanity blossoms within the unique context of a classroom as shaped by the knowledge, experiences, and values of the individuals therein.

Such a wide range of viewpoints regarding the degree or need for educational reform will inevitably lead to yet another underlying debate: how does one define good? Unfortunately, the minute and, often times, ignored discrepancies surrounding the definition for the simple term good expound to disagreements and debates about such educational issues as essential knowledge and skills, best practices, equality of opportunities, and tailored-curricular choices. The relative nature of labeling any given object or system as good inherently exposes the resulting criterion's fatal flaw: good, like the adage for beauty, lies within the eye of the beholder. Thus, reformation within any given educational system seeking to provide positive or good results dynamically depends upon the underlying philosophy -whether ideals of equality or individual choice - driving the qualification of good results.

Regardless of the wide range of voices seeking to determine the qualities which guide reformation, the eventual determination of whose voice leads the charge for reform plays a key 
role in the success or failure of any given attempts at change. The most important voices within any given debate on education reform arguably fall to the educators and the parents of the students within the school. Sliwka and Istance (2006) examined both the global and local involvement of parents within the education system. Ultimately Sliwka and Istance determined that, while parents want a representative voice within the policies and practices of a school, parents expect administrative personnel to take the lead within the decision making process (p. 42). Thus, the responsibility of sifting through the voices of concern falls upon the leaders of that institution.

In their article "What Makes a Good School," Lipsitz and West (2006) seemingly agree with the findings of Sliwka and Istance. Lipsitz and West argue that "the truly high-performing school sits at the intersection of academic excellence, developmental responsiveness, and social equity" (p. 58). They further postulate that one individual or select group of individuals maintain the general traffic flow in and around such an academic intersection. Accordingly, they qualify that good schools are led by "risk-taking, visionary, practical leader[s]" (p. 64). In so doing, such schools better identify localized-improvement needs, solicit stakeholder insights for consideration, and maintain a consistent application of the term good.

Given that parents expect administrators to lead and that good schools depend upon leadership (Lipsitz \& West, 2006; Sliwka \& Istance, 2006), the success of any given educational reform will be tied to the leadership therein. However, the governance of a school and the leadership surrounding school reform may not always be one and the same. Some advocate for a bottom-up approach to school improvements wherein the teaching staff takes the lead in reform (Patterson \& Patterson, 2004). Others argue for a business model wherein decisions for reform 
are made and dispensed from a top-down approach. Regardless of whether the impetus for reform efforts originates from teachers or from administration, research suggests that reform ultimately depends on leaders who both understand the nature of change and inspire others to implement change - whether in curriculum or practice (Dagley \& Gazda, 1984; Louis \& Wahlstrom, 2011; Patterson \& Czajkowski’s, 1979).

Given the weight of success resting upon the shoulders of administrators requiring reform of their teaching staff, the following questions provide direction in assessing the implementation of curricular reform at Greenbrier Christian Academy by the teaching staff therein. Are the teachers seeking to improve the curriculum to which they have been entrusted? Have their attitudes and perceptions regarding the change in template evolved over time?

\section{Definition of Terms}

Reform - The term reform holds a range of definitions as designated by a host of professionals within the field of education (Feldmann, 2005; Haywood, 2004). The term may refer to efforts made toward specific improvements within a singular aspect of the education system (Asghari, Shahvarani, \& Medghalchi, 2011; Branyon, 2012). The term also may represent, whether in part or whole, efforts to completely alter the process of education (Cruz, 2010; Wiggins, 2011). Ultimately, all definitions for the term reform center upon the idea of change. Additionally, one should note that such change depends upon the individuals tasked with implementing the specific reform measures (Evans, 2001). The impact both of individuals on reform and of reform measures on individuals will be explored in detail in the Literature Review section of the research document. Due to the wide range of potential definitions for 
reform, the term, within the context of this document, primarily shall be defined as efforts made to improve certain aspects of the current educational system.

Understanding by Design - Referencing the research work amassed by researchers Grant Wiggins and Jay McTighe (2005), Understanding by Design provides educational practitioners with both a conceptual method and practical model through which teachers might develop, implement, and assess student understanding pertaining to a given curriculum (p. 1-11). Sometimes referred to as "backwards design," Understanding by Design involves a precise, methodical approach to planning instruction. The approach advocated by Wiggins and McTighe involve three distinct, sequential stages of curricular design: 1) establishing the desired outcomes and objectives, 2) identifying the types of tasks and evidence one expects to see of the learner, and 3) mapping out the progression of activities and instruction through which the student will undergo throughout the learning process (p. 13-33). The template offered by Wiggins and McTighe served as a guide for the development of the Unit Plan Template which served as the focus of curricular reform at Greenbrier Christian Academy (p. 327-332).

Unit Plan Template - The current tool utilized by the upper school teaching staff at Greenbrier Christian Academy. See Appendix A for an example of a blank Unit Plan Template developed for implementation at the school. The unit plan marked a dramatic transition for the teaching staff away from the weekly lesson plan template which had previously been in use for over a decade at the school. As alluded to in the definition of Understanding by Design, the Unit Plan Template was based on the template design offered by Wiggins and McTighe with a few specific modifications. Such modifications include, but are not limited to, inclusion of a section for Biblical Integration of the unit material, inclusion of a fourth stage promoting teacher 
reflection, and expansion of Stage Three's lesson planning to include a day-by-day record of instructional planning for the entire unit of study.

Weekly Lesson Plan Template - The former tool utilized by the upper school teaching staff at Greenbrier Christian Academy. See Appendix B for an example of a blank lesson plan template formerly used by the teaching staff to record their daily lessons. The weekly lesson plan had been in use at the school since the early 1990's. The template had been modified and expanded over time to include the Virginia Standards of Learning and information cross referencing the internally-created, departmental goals in compliance with accreditation standards set by the Association of Christian Schools International (ACSI). Ultimately, the template depicted the plans of teachers to distribute content on a daily basis as summarized in a weekly chart. While the plan did include objectives tied to each day's instruction, the plan lacked a defined connection between those objectives and the daily method for instruction leading to the eventual assessment of the content.

Concerns-Based Adoption Model - Developed at the University of Texas Research and Development Center for Teacher Education in the late 1960's, Roach, Kratochwill, and Frank (2009) indicate that the Concerns-Based Adoption Model (CBAM) provides researchers with criteria against which the attitudes and behaviors relative to those involved in specific reform efforts might be categorized or predicted. The model identifies three distinct frameworks against which the implementation of reform efforts might be described. The first framework, Stages of Concern, provide researchers the ability to categorize the attitudes and feelings held by teachers involved in reform into six distinct stages. The next framework, Levels of Use, provide researchers with the ability to categorize the degree of engagement that the teachers exhibit with 
the reform tools. The final framework, Innovation Configurations, acknowledges that any given reform effort will be subject to adaptations as a result of individualistic implementation practices of the teachers involved in the change process (p. 303-314).

\section{Statement of the Problem}

Chester E. Finn Jr. begins his article "Why Private Schools Are Dying Out" with the following foreboding forecast - "Private education as we have known it is on its way out, at both the K-12 and postsecondary levels" (2013, para. 1). Using statistical data gathered from the National Center for Education Statistics, Finn identifies a grim reality faced by many private and non-profit educational institutions: declining enrollment. Statistical data confirms the suspicions of many private school administrators: the enrollment of students in such K-12 organizations has been steadily shrinking for over a decade. When one looks closely at data provided by the National Center for Education Statistics (2013), one will notice that the shrinking of enrollment for students in grades 9-12 began in 2008 and is projected to continue in a downward trajectory over the next several years (National Center for Education Statistics, 2013, Table 1). While religiously affiliated private schools hold the largest share of private school students $-77.2 \%$ between Catholic and other religious institutions (National Center for Education Statistics, 2013, Table A-5-3), the shares of enrolled students in private institutions does not negate the declines in enrollment that such institutions have faced over the past five years. Finn concludes his article with the following questions - "Can run-of-the-mill private schools and colleges reboot? Can they change themselves ... enough to brighten their own futures?" (2013, para. 18).

Those schools which seek to answer such questions relative to the need for change have consistently sought to reform their institution once they have identified areas needing either 
improvement or change. Greenbrier Christian Academy, an ACSI/SACS accredited school serving students from P3 through the completion of their senior year, exemplifies one such institution. The school first opened its doors on September 6, 1983, following two interest meetings held merely three months prior to the opening of the school (Parchments, 1984). At that time the school's founder and superintendent, Dr. H. Ron White, led the charge for educational reform in the city of Chesapeake, Virginia, by creating the first independent Christian school in the Hampton Roads area of Virginia (Ward, 2012). The school began that first year with 197 students, doubled the enrollment within two years, and currently services 555 students. However, while the enrollment of the school has shifted over the past three decades, the goals of the school have remained constant: "[to] thrust forth not only spiritual leaders within the pastorates and other full-time ministries of Christian service, but ... also provide students with the abilities necessary to tackle the professional requirements of law, medicine, and other highly specialized professional areas" (Parchments, 1984). Throughout the thirty year history, Greenbrier Christian Academy has consistently asked the question: what areas of the school need to be reformed in order to remain a source of high academic standards which, in turn, prepare students for the future that God has set for them?

During the spring of 2011, the aforementioned question would be once again posed during a conversation between Dr. White and me, the middle school principal. Central to the question resided a growing concern among members of the administrative team at Greenbrier Christian Academy relative to the continuity between the school's curriculum and the upper school teacher's weekly lessons. Despite six curriculum binders, each three inches in size, packed tightly with content-specific purpose statements, goals and objectives, scope and 
sequence documents, and Virginia's Standards of Learning objectives, the connection between such documents and the teacher's day-to-day lesson plans were, at best, murky. In some cases the transition between teaching staff left little evidence of continuity between what was intended and what was implemented. Unfortunately, in many cases, the new teachers coming to teach at the school would set aside the binder of curricular documentation in favor of an isolationistic planning approach. In such an approach the topics of study would be dictated by the textbook found within the classroom. Worst yet, some veteran teachers who assisted in the development of the guiding curriculum documents, rarely consulted the documents as they planned their weekly lessons. Thus, the conversation between the superintendent and myself revolved around one essential question: how will the school initiate and maintain teacher engagement with the established curriculum? As such the conversation on that spring afternoon marked the beginning of curriculum reform at Greenbrier Christian Academy.

In the spring of 2011, I was completing my fourth year as middle school principal at Greenbrier Christian Academy. I had entered the position under the guidance of Dr. White after having completed ten years in the classroom. While I did hold an undergrad degree in teaching, I did not hold the educational credentials normally attributed to those in the position of a school principal. In an effort to bolster such credentialing, I was nearing the completion of master's level courses at Cedarville University. During the fall of 2010, my course work introduced me to concept-based curriculum and a method of teacher planning known as backwards design. Due to my position and recent exposure to curriculum design, the proposed answer to the issue of continuity between instruction and curriculum would be birthed from personal experiences. 
Thus, during the conversation in the spring of 2011, I proposed utilizing an alternative method of teacher planning based upon Wiggins and McTighe's (2005) research on Understanding by Design. The goal in reforming the template used by the upper school teaching staff was to create a dynamic curriculum wherein the teacher would review, refine, and reuse the curriculum documentation previously prepared. After viewing a sample of the Unit Plan Template and evaluating the perceived improved connection between curriculum documentation and curriculum implementation, the superintendent approved the proposed curricular reform in the spring of 2011. Thus, the process of exploring and implementing curriculum documentation reform began to be initiated at Greenbrier Christian Academy.

The curricular reform initiated during the 2011-2012 school year was mandated for implementation during the 2012-2013 school year and continues during the current 2013-2014 school year. While the administrative staff is aware that the teachers are using the tool to prepare and record the lessons of each unit of their respective curricula, the question to what degree are the teachers engaged with the curriculum documentation tool remains to be answered. Are the teachers seeking to improve the curriculum to which they have been entrusted? Have their attitudes and perceptions regarding the change in template evolved over time? Answers to such questions should provide the administrative staff insight to the success or failure the curricular reform efforts which have dominated the teachers' lives over the past two and a half years.

\section{Scope of the Study and Delimitations}

The mixed method case study will center on the curriculum reform efforts of the upper school faculty and administrative staff at Greenbrier Christian Academy located in Chesapeake, Virginia. The thirty-year-old school currently services 276 students in grades 6-12 using a total 
of twenty-nine full and part time teachers, two principals, one academic dean, and one superintendent. Accredited by the Association of Christian Schools International (ACSI) and the Southern Association of Colleges and Schools (SACS), Greenbrier Christian Academy meets and/or exceeds standards set by both accrediting agencies. While the process of curricular reform was initiated during the spring of 2011, the implementation of those reforms currently are ongoing for faculty and staff. The study of Greenbrier Christian Academy's curriculum reform will use primarily qualitative research methods (including surveys and historical documents).

Several factors impact the potential validity of this research study including sample size, confounding variables, and researcher bias. First, the sample size shall be addressed as the process has spanned several academic years. During the first semester of the 2011-2012 school year, twenty-nine teachers were tasked with implementing a trail usage of the Unit Plan Template. Of the twenty-nine teachers, twenty-four teachers provided feedback to the administrative staff via a teacher survey tool (see Appendix C for the 2011 survey instrument used to analyze the teacher's usage and views of the then proposed reform of curricular documentation). Of the twenty-four teachers who provided feedback to the administrative staff regarding the proposed curriculum reform, twenty teachers would continue as employees of the upper school during the 2012-2013 school year when the Unit Plan Template would become the standard curriculum template for the upper school teaching staff. Of those twenty teachers who worked to implement the Unit Plan Template during the 2012-2013 school year, nineteen teachers continued on staff for the 2013-2014 school year and have been involved with the curriculum reform process from the beginning of the process to the present date. However, of the nineteen potential participants, only sixteen teachers ultimately participated in the research 
project. Thus, while the size of the population being studied remained constant at twenty-nine individuals, the passage of time has slowly eroded the sample size from twenty-four to sixteen. As such the sample size falls below the suggested sample ratio of Krejecie and Morgan (as cited in Johnson \& Christensen, 2008, p. 242).

A second factor impacting the potential validity of this research study is confounding variables. The confounding variables within this research study include, but are not limited to, teacher turnover, increased teacher responsibilities due to rising fiscal restraints of the school, and extrapolation of initial survey data not fully intended to correlate with survey principles establish in the Concerns-Based Adoption Model. As alluded to in the section addressing sample size, teacher turnover has naturally occurred at Greenbrier Christian Academy both at the conclusion of and during the course of each academic year: specifically between the fall of 2011 to the fall of 2013. During the pilot study of 2011-2012, three teachers would not complete the year; four would not return the following year. During the first year of implementation (20122013), one teacher would not complete the year, two teachers would face extended absences due to medical leave, and another three teachers would leave their roles at the conclusion of the school year. By the start of the second year of curricular reform implementation in August of 2013, a total of ten new hires would join the teaching force utilizing the Unit Plan Template.

Another confounding variable challenging the validity of this research study undoubtedly must be the increased responsibilities placed upon the teachers and administrative staff at Greenbrier Christian Academy. Due to a variety of factors, many individuals had taken on more responsibilities in order to fill in the gaps normally assigned to former employees of the school. During the 2011-2012 school year, the school's curriculum director would leave midyear forcing 
a distribution of responsibilities among the administrative staff of the school. One week prior to the start of the 2012-2013 school year, one middle school teacher would resign her position which in turn forced two teachers to take additional classes (in both cases overloading the teachers with three to four courses). The director of activities would leave his post during the summer of 2013. His duties would then be spread out among both faculty and administrative staff. Finally, the school would ultimately face reaccreditation with ACSI and SACS, whose accreditation standards also have faced reform over the past two years, during the spring of 2014. Taken all together, the faculty and staff at Greenbrier Christian Academy faced job-related stresses due to increased or deferred responsibilities throughout the process of curriculum reform.

The final confounding variable challenging the validity of this case study remains the extrapolation of data from earlier teacher surveys. The data gathered from that initial survey was not fully intended to align with the survey principles undergirding the Concerns-Based Adoption Model. As previously mentioned, CBAM provides researchers with a method of examining the perceptions and attitudes of research subjects throughout any given process of change or reform based on six stages of concern (Khoboli \& O'toole, 2012). Ideally, the initial survey given to teachers soliciting their feedback regarding the type of curricular reform being piloted would have included prompts that lead teachers to identify themselves within one of the six stages of concern. However, the initial survey given sought information on a variety of items including the teacher's open responses surrounded perceived value/usefulness of the template and potential suggested alterations to the template. Within such open responses, one perceivably can extrapolate information to align within one of the six stages of CBAM. Given, however, that the 
focus of the research will be based upon the teacher's current perceptions and attitudes about the curricular reform at the school, the connection between past survey data and contemporary data should not invalidate the study. Instead, the additional data from the earlier survey should assist in providing a more comprehensive view of the data gained through the application of CBAM within the study.

One of the final, and potentially more significant, limitations within this historical research study remains researcher bias. My affiliation with Greenbrier Christian Academy began in the fall of 1986 as a sixth grade student. I graduated in the spring of 1993 and returned to the same school as a full time teacher in the fall of 1997. I spent ten years in the classroom prior to transitioning to the position of middle school principal in the fall of 2007. Just this fall of 2013, I expanded the titles of my connection with the school from alumnus and employee to that of a GCA parent. Add to this connection the fact that my mother has been employed by the school in one capacity or another since the fall of 1987. My wife, employed at the school since the fall of 1998, serves as the yearbook advisor and works within an administrative office of the school. My sister and brother-in-law have both been employed by the school since the fall of 1992 having sent their children, currently a junior and a freshman, to the school throughout their academic careers. To this end, I represent a researcher who personally holds an expansive perspective of the institution being studied.

Additionally, as the initiator of the curricular reform, I hold an intimate connection to the topic of study that could potentially skew my perspective. To be clear, the topic of study central to this thesis is not whether or not an adaptation of Wiggins and McTighe's understanding by design planning template surpasses the previous planning template utilized by the teaching staff 
of Greenbrier Christian Academy. Instead, the topic of study centers on the attitudes and perceptions of those involved in the process of implementing reform at Greenbrier Christian Academy. While the researcher is afforded the opportunity to frame the reporting of the findings from this internal school study, such a report will be shaped by the perspectives of a variety of participants involved in the reform process.

To provide some validation of the researcher's coding of the participants' survey responses, I propose that the coding of the responses be verified by additional administrative members. Individuals, either affiliated with the school or serving in administration in other schools, will view the coding of comments as assigned by the researcher and identify his/her agreement with each individual code. In so doing the researcher's potential for bias can be minimized. Furthermore, the data gained by the coding of participants responses will be quantified to assist the researcher in the process of data analysis. Thus the results of this case study and discussion thereof should represent more than the researcher's opinion or bias.

\section{Significance of the Study}

The proposed case study provides valuable insight for the administrative staff at Greenbrier Christian Academy regarding the teacher's perceptions, attitudes, and current engagement relative to the ongoing curriculum reform. The study of the curricular reform efforts rests upon two essential questions. Are the teachers seeking to improve the curriculum to which they have been entrusted? Have their attitudes and perceptions regarding the change in template evolved over time? As such, the study holds value by informing future administrative staff and teachers who inevitably will undergo or seek to implement educational reforms perceived as necessary for Greenbrier Christian Academy. To a lesser degree the case study will either 
validate or contradict previous findings reported in literature regarding educational reform and the process thereof.

\section{Methods of Procedure}

The proposed case study of the curricular reform efforts at Greenbrier Christian Academy relies upon interpretation of open-ended survey results, selective interviews, and analysis of curriculum documents compiled thus far in the transition to the Unit Plan Template. The criteria used to interpret the responses from both the open-ended questions on the survey and questions asked during the interviews will be based upon criteria established within the Concerns-Based Adoption Model. Specifically, the assessment of the participant's attitudes will be based upon the characteristic features of the Stages of Concern. Figure 1 provides a summary of the Stages of Concern as provided by Roach, Kratochwill, \& Frank (2009). Additionally, the assessment of the participant's current engagement with the curricular planning tool will be based upon the Levels of Use framework established in the Concerns-Based Adoption Model. Figure 2 provides a summary of the Levels of Use as provided by Roach, Kratochwill, \& Frank (2009).

During the pilot study of the Unit Plan Template, an internal survey (Appendix C) was developed and used in order to assess several factors including the teacher's views on curricular impact within the classroom and personal perceptions regarding the template. While the pilot survey was not based upon the Stages of Concern framework found in the Concerns-Based Adaption Model, the teacher's open-ended responses can reveal key terms and phrases attributed to the specific stages of concern. As suggested by Hall and Hord (1987), the open-ended responses provide valuable documentation of the teacher's statements of concern relative to the, at that time, proposed curricular reform (as cited in Roach, Kratochwill, \& Frank, 2009, p.305- 


\begin{tabular}{|c|c|c|}
\hline $\begin{array}{l}\text { General } \\
\text { category of } \\
\text { concern }\end{array}$ & & stinct stage of concern with general description \\
\hline \multirow[t]{3}{*}{ Impact } & $\begin{array}{l}\text { Stage } 6- \\
\quad \text { Refocusing }\end{array}$ & $\begin{array}{l}\text { The focus is on exploration of more universal benefits from } \\
\text { the research-based practice including the possibility of } \\
\text { major changes or replacement of intervention with a } \\
\text { more powerful alternative. }\end{array}$ \\
\hline & $\begin{array}{l}\text { Stage } 5- \\
\quad \text { Collaboration }\end{array}$ & $\begin{array}{l}\text { The focus is on coordination and cooperation with others } \\
\text { regarding use of the research-based practice }\end{array}$ \\
\hline & $\begin{array}{l}\text { Stage } 4- \\
\quad \text { Consequence }\end{array}$ & $\begin{array}{l}\text { Attention focuses on impact of the research-based practice on } \\
\text { students in his or her immediate sphere of influence. } \\
\text { The focus is on relevance of the practice for students, } \\
\text { evaluation of student outcomes, including performance } \\
\text { and competencies, and changes needed to increase } \\
\text { student outcomes. }\end{array}$ \\
\hline Task & $\begin{array}{l}\text { Stage } 3 \text { - } \\
\quad \text { Management }\end{array}$ & $\begin{array}{l}\text { Attention is focused on the processes and task of using the } \\
\text { research-based practice and the best use of information } \\
\text { and resources. Issues related to efficiency, organization, } \\
\text { management, scheduling, and time demands are the } \\
\text { utmost concern. }\end{array}$ \\
\hline \multirow[t]{2}{*}{ Self } & $\begin{array}{l}\text { Stage } 2- \\
\quad \text { Personal }\end{array}$ & $\begin{array}{l}\text { Individual is uncertain about the demands of the research- } \\
\text { based practice, his or her inadequacy to meet those } \\
\text { demands, and his or her role with the practice. This } \\
\text { includes analysis of his or her role in relation to the } \\
\text { reward structure of the organization, the decision- } \\
\text { making process, and consideration of potential } \\
\text { conflicts with existing structures or personal } \\
\text { commitments. }\end{array}$ \\
\hline & $\begin{array}{l}\text { Stage } 1- \\
\quad \text { Informational }\end{array}$ & $\begin{array}{l}\text { A general awareness of the research-based practice and } \\
\text { interest in learning more detail about it is indicated. } \\
\text { The person seems unworried about himself or } \\
\text { herself in relation to the practice. She or he is } \\
\text { interested in the substantive aspects of the research- } \\
\text { based practice in a selfless manner such as general } \\
\text { characteristics, effects, and requirements for use. }\end{array}$ \\
\hline Unrelated & $\begin{array}{l}\text { Stage } 0- \\
\quad \text { Awareness }\end{array}$ & $\begin{array}{l}\text { Little concern about or involvement with the research-based } \\
\text { practice is indicated. }\end{array}$ \\
\hline
\end{tabular}

Figure 1 Stages of Concern ( organization and summary of the stages as provided by Roach, Kratochwill, \& Frank, 2009, p. 304)

306). Therefore, the internal survey offers valid insight to the participant's initial attitudes and perceptions as characterized by the Stages of Concern framework.

A follow-up survey (Appendix D) of the remaining nineteen participants will offer further validation of the researcher's interpretations of the internal survey by asking participants to describe their initial attitudes and perceptions of the Unit Plan Template. Furthermore the 


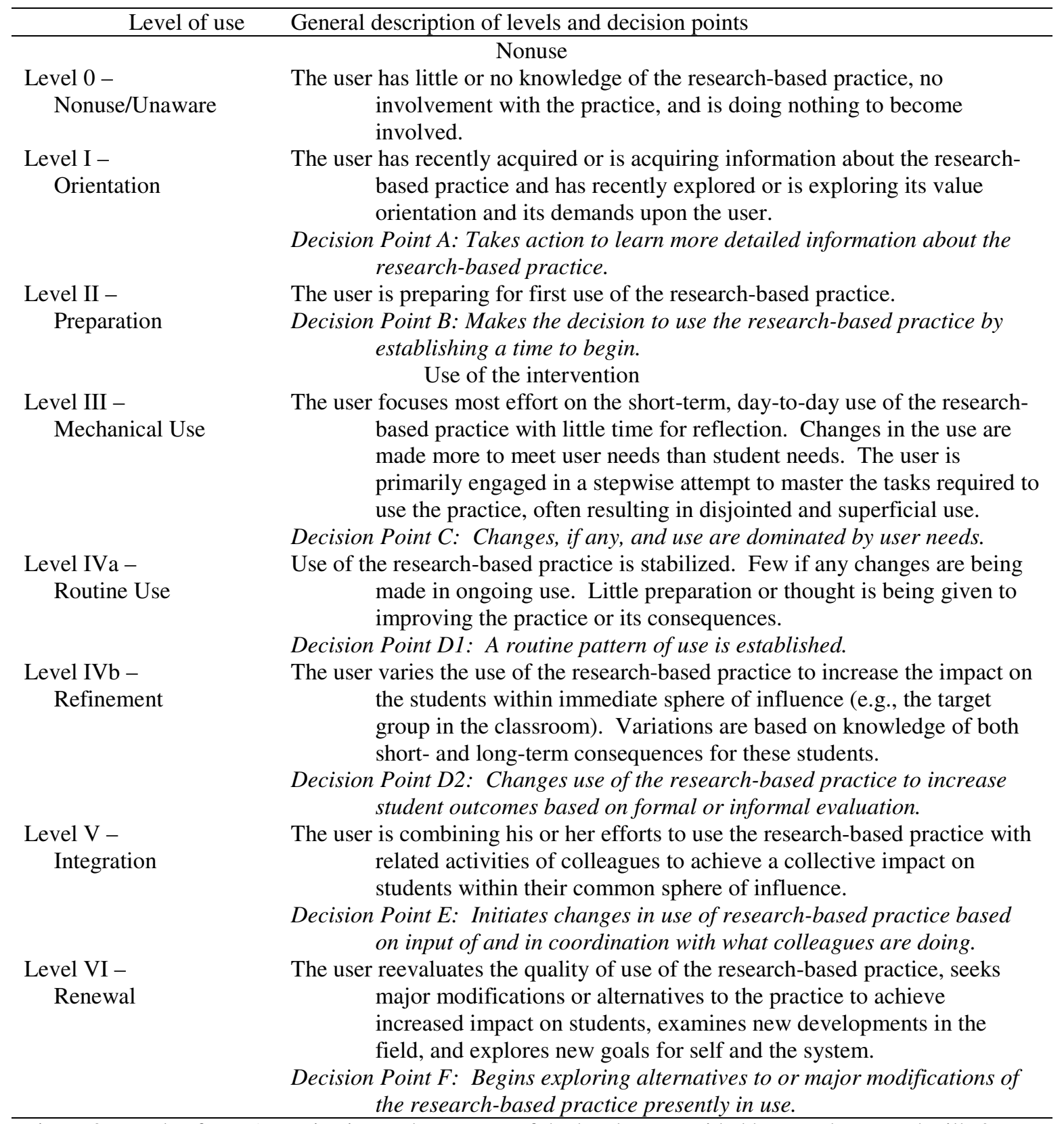

Figure 2 Levels of Use (organization and summary of the levels as provided by Roach, Kratochwill, \& Frank, 2009, p. 310)

follow-up survey will ask participants to identify and describe any evolutions in their attitudes or perceptions of the Unit Plan Template since the pilot program during the 2011-2012 school year. Such tailored questions should supply appropriate data as to how the attitudes and perceptions of 
participants have evolved throughout the reform implementation process at Greenbrier Christian Academy.

The follow-up survey (Appendix D) also provides participants the opportunity to identify their degree of engagement with the Unit Plan Template. Statements recorded in the open-ended question relative to the participant's current usage of the template should provide a range of statements that demonstrate the participant's degree of engagement when analyzed using the Levels of Use framework established in the Concerns-Based Adoption Model. Written claims regarding engagement can be verified using a comparison of curriculum documents created during the first year of implementation with the curriculum documents currently being produced by the same participants. Such cross referencing of survey responses and curriculum documentation should produce an answer to the current degree of engagement with the curricular reform measures. Additionally, cross referencing should assist in identifying areas of weakness which need to be addressed by the administrative staff at Greenbrier Christian Academy.

Throughout the course of analysis, the researcher may identify certain participants whose evolution in attitude or degree of engagement best demonstrates the findings of the survey. Those participants may then be interviewed to further exemplify the curricular reform efforts being analyzed within this study. Such testimonials may not only verify research previously conducted on educational reform but also add to any conclusions regarding the lessons of reform which might assist future reform efforts at Greenbrier Christian Academy. 


\section{Chapter 2: Literature Review}

Reform within the walls of school buildings and the minds of educators glitter the pages of educational history. To best understand the efforts made toward implementation of reform within the walls of Greenbrier Christian Academy, a study of historical examples, philosophical underpinnings, and psychological implications should illuminate the contextual foundation for the curriculum reform currently underway.

The annuals of American education seem to collectively demonstrate a push toward not only a literate and productive society but also a continuously reformed method by which such a task would or should be achieved. In his extensive overview of the American educational system, Joel Spring (2005) offers readers with several examples of such a continuous reform. The first noteworthy reform within the American system inescapably falls to the transition towards the "Common School" wherein the fledgling country's youth would be indoctrinated with the beliefs and values of the new government thus making them model citizens and ushering in the ever elusive utopian society. Horace Mann, often titled the "Father of the Common School Movement," played a key role in establishing the goals and objectives driving the common school movement. Spring parallels the social salvation offered by the common school and the religious crusades of the same period postulating that Mann's push for the common school represented a rejection of the Calvinistic ideology into which Mann had been born and raised. Thus, in establishing the common school within the young country, Mann sought to scrub the instructional content of controversy for the sake of universal societal application (be the controversy religious or political in nature) (p. 73-84). 
While the impact of the common school movement can be identified within the structure of the modern school system, the driving goals and objectives for such reform remain largely unmet and unfulfilled in both past and present society. In many ways the rise of the common school provides continued context to the development and influence of contemporary reform efforts in education. However, the lessons regarding reform within America's educational past are not isolated to the early impact made by Horace Mann.

According to Spring (2005), the restructuring reforms of the nineteenth century provided the necessary context within which our modern governance model of the education system would be formulated. Spring suggests that the classification of students within "graded schools" (grouping learners by age and readiness levels) produced an environment which required general supervision of instruction and curriculum. Stated more specifically, as the push for uniformity among schools dotting the landscapes of towns and communities of a state increased, so did the push for bureaucratic supervision and oversight within those once independent, single-roomed schoolhouses (p. 150-157).

However, as the governance model for grade schools took firm root within the educational landscape, reforms would once again shift back to the essential questions of what equates to an educated society and how do schools produce that society. In his article "TwentyFive Years of Erosion in the Curriculum: The Committee of Ten to the Cardinal Principles, 1893-1918," Feldman (2005) introduces the claim that the competing philosophies which ignited the debated reforms from 1893-1918 ultimately produced an unintended deterioration within the education system. 
Beginning with the Committee of Ten and the push for standards driven content, Feldman concludes that conflicting subcultures and perceived missions resulted in the weakening of standardization and academic rigor originally intended by the Committee of Ten. Next, Feldman addresses the shift away from universalized, content-focused standards to a culturally driven, student-centered approach of education as a result of Franklin Bobbitt's book The Curriculum and the Cardinal Principles of Secondary Education. However the student-centered philosophy would eventually give way to those advocating social efficiency reforms, thus supporting and reflecting the industrialized society of the time. Of course, social efficiency would ultimately meet challenge from "Reconstructionists" seeking to reform all of society through the content and lessons within the classroom. Through each of the reform generations, Feldman demonstrates the problematic nature of creating lasting, universal reform given the competing goals, objectives, and philosophies of those involved with education.

\section{The Philosophies Behind Reform}

While the calls for reform have yet to wane within the education system, the underlying philosophies appear to represent bedrock of two shifting tectonic plates within education theory upon which the banners of reform are mounted. Lee and Ready (2009) identify the warring philosophies of education as democratic idealism verses individual choice. Democratic idealism seeks to establish an equitable and uniform educational system. Such idealism provides all students with the same opportunities to acquire the standardized knowledge and skills necessary to freely select a productive position in American society. Individual choice, on the other hand, seeks to provide a wide array of knowledge and skills from which the student may self-select based on his/her own abilities, motivations, and interests, thus leading to his/her productive 
position in American society (p. 150). While both philosophies seek to equip the learner for a future position within society, each views the control over the learner's acquisition of the necessary knowledge and skills for that pending future differently.

Take for example H. Carl Haywood's (2004) call for educational reform. Haywood begins his argument for reform with the statement that while "almost everybody agrees that educational reform is needed, ... there is not universal agreement on the nature of the problems, and certainly not on the remedies" (p. 231). To this end Haywood offers three reasons for his proposed approach to educational reform: (1) the persistent discontent with the current educational system as revealed through literature; (2) the organic nature of content within the current educational system as a result of a continuously shifting culture which dictates the type of information to be transferred; and (3) the restrictive goals of the current educational system which limits the learner to extrinsic vocational preparation. In order to address the identified challenges to the current educational system, Haywood proposes a shift toward a "transactional perspective." The transactional perspective is characterized by the transfer of any given knowledge based upon insights relative to human nature and development. Ultimately, he believes that addressing the learner's motivation to learn and offering the learner the logical structures for organizing new information will address the dissatisfaction, organic nature, and restrictiveness of education (p. 231-250). Thus, Haywood falls within the camp of those espousing individual choice in his attempts to free the learner from the constraints of a tightly controlled curricular offering.

Counterbalanced to the philosophy driving Haywood's call for reform stands a growing tide of professionals seeking to implement the Common Core Curriculum within the educational 
system of the United States. The Common Core Curriculum (or Common Core State Standards) represents the collaborative efforts between politicians, education professionals, administrators, and teachers spanning at least forty-five states. Additionally, the Common Core attempts to provide uniform standards by which all students exiting high school would be prepared to enter college or the public work force (Rust, 2012). To this end the Common Core movement clearly represents the philosophy of democratic idealism as defined by Lee and Ready (2009).

Furthermore, the attempts to quell the mounting arguments against the yet to be proven implementation of the Common Core State Standards (Katzman, 2012) has inspired an offensive push by democratic idealists as evidenced by the case study work of Jill B. Branyon. Branyon (2013) analyzed the longstanding, national curriculum in the nation of Kenya in an effort to extrapolate key concepts which support the implementation of a universalized curriculum within the United States. As a result of her study, she found that common standards do not ensure universal application of those standards. In fact she identifies the biases and perceptions of individual teachers as impacting the implementation of national standards (p. 45). Interestingly enough regarding the same issue of the Common Core Curriculum, John Katzman (2012) argues that such an idealistic approach to education does not work within the United States due, in part, to the disparity between the values that such ideals represent and the values held by an individualistic culture (p. 38). Thus, once again we see the warring philosophies battling for position within the realm of educational reform.

\section{The Psychology of Reform}

Based on a cursory review of educational reforms in the early history of America, a peek into some contemporary calls for reform, and an understanding of the two battling philosophies 
pushing for differing versions of reform within the American culture, one can better understand the psychological implications associated with reform. Ultimately reform within any organization requires a change in practice among the individuals who are involved within the organization. Edgar H. Schein in his book Organizational Culture and Leadership identifies that reform and change within any given culture is often met with resistance by individuals who may simultaneously recognize the benefits of reform yet reject the unsolicited changes which accompany such innovation (as cited in Evans, 1993). Thus, one of the driving obstacles to implementing any type of lasting reform in deed becomes the interdependent relationship between those pushing for reform and those enacting the tenants of reform.

Dr. Marlow Ediger addresses those individuals who serve in administration and initiate reforms in his article "Change and the School Administrator" relative to the proper perspective regarding the interdependent relationship of those involved in change implementation. Ediger begins his perspective proposal by highlighting George Friedrich Hegel's philosophy of dialectical reasoning which suggests that each new thesis will produce a contradictory antithesis resulting in cyclical conflict between the two viewpoints until such time that a suitable synthesis of terms has been reached. When Hegel's philosophy is applied to the reforms in education, Ediger suggests that administrators view change as a long-term process which moves those involved in the implementation of reform from the actual to the ideal (1998). Therefore, those who bear the responsibility of identifying areas in need of reform and of initiating the acts of reform should hold a long term view of the change process bearing in mind the tension that will inevitably accompany reform implementation. 
Without question the initiations of reform implementation fill the pages of educational journals and litter the policy manuals of countless school organizations. The challenge for many administrators seeking reform indeed lies within both the long term view of the process and the sustainability of any given reform efforts. Researchers at the University of Florida investigated the qualities which lead to or complicate the sustainability of reform efforts. Their case study investigation spanned a five year period from 1998-2003 of intensified analysis of one middle school in southeast Florida seeking school wide reform in the area of inclusion. At the conclusion of the study, the researchers confirmed the existing literature which suggested that sustainability of any given reform effort depends heavily upon the stability of employee retention, the provision of adequate resources, and the leadership skills exhibited by administrative members (Sindelar, Shearer, Yendol-Hoppy, \& Liebert, 2006).

\section{The Leadership of Reform}

Since the development of the Common School, calls for reform within a school's walls typically are generated and authorized by a school's administrative team when not mandated by state policy leaders. In light of the current curriculum reform efforts by the upper school's administrative team at Greenbrier Christian Academy, a study of the roles and the challenges faced by leaders responsible for educational reform should provide guidance relative to the effectiveness and sustainability of the curriculum reform currently underway.

In the article "Alternatives of Educational Reform: Responses of Selected Leaders," Dagley and Gazda (1984) identify that in the area of reform "there is no substituted for effective leadership" (p. 223). The two men continue to qualify effective leadership as individuals who move beyond the comfortable to identify and enact change and who work with a range of 
individuals on varying levels to achieve the intended purposeful reforms (p. 222-223). In truth the leadership at any given institution holds a crucial impact on the successfulness of both the mission and the direction of that institution. Yet, the types of leaders and the applied skills of leadership can be as diverse as the countless mission statements guiding educational institutions in the United States. What then fosters the implementation of successful reform within a school beyond the generalities of vision casting and inspirational communication as provided by the school's administration?

Louis and Wahlstrom (2011) propose a culture of trust as a key factor in the successful implementation of reform. Within their article "Principals as Cultural Leaders," Louis and Wahlstrom echo the struggle that many educators face. Rapid change inevitably increases the challenges faced by educators who are seeking to address and adapt to the demands faced by schools attempting to keep pace with the changes within society (p. 54). Concentrating on the relationship characteristics that exist between administration and teaching staff, the two researchers identify a key difference in perspective between the two parties relative to the extensiveness of viewpoints. Accordingly, teachers tend to hold a short term view of the circumstances surrounding them. Such was demonstrated by the type of questions typically posed by teachers. The questions reflected immediate issues or concerns - how will such changes influence, impact, and/or alter my work this year with the current students assigned to my courses. Conversely, administrators often overlook the immediate implications of reform holding instead to a long term view of the issues and the potential improvements expected to come from any given reform. Thus, Louis and Wahlstrom advise those in administration to foster a culture of trust to increase the potential success of reform efforts. 
Louis and Wahlstrom's suggestion to bolster trust between administration and teaching staff seemingly align with earlier research provided by Greenfield who suggests reform efforts fail or are stymied as a result of several internal and external factors. Specifically, Greenfield identifies five potential points of failure within the area of reform implementation: 1) weak curricular leadership, 2) disagreement regarding the need for change, 3) lack of funding, 4) teacher turnover, and 5) collective commitment and participation (as cited in Ediger, 1998, p. 543). Of course Greenfield's views echo research from Patterson and Czajkowski's (1979) article "Implementation: Neglected Phase in Curriculum Change" which traces the point of failure back to administration. The two researchers suggest that, while administration does perform in depth development and planning for curriculum reform, many in leadership fail to oversee and ensure teacher implementation efforts for a variety of reasons.

Patterson and Czajokowski (1979) suggest that school leaders plan for at least two years of implementation for any given curricular reform and adopt an appropriate strategy for implementation based on teacher commitment, perceived need for change, and additional external factors influencing change. The two researchers identify three strategies for reform implementation which may be employed independently or corporately to increase the success of reform efforts. In brief leaders may employ a "strategy of reason" which provides the faculty with an understanding of the needs and objectives driving the current push for reform (p. 205). A "power strategy" might be employed when the faculty generally seems resistant and change is mandated by leadership (p. 206). Finally, the researchers suggest that one of the most effective strategies for reform implementation is "influence" wherein leaders attempt to use classic 
conditioning (rewards) to establish patterns of behavior which lead to reform implementation ( $\mathrm{p}$. 206).

\section{The Business of Reform}

Given that research suggests the success of reform lies with the leadership's direct involvement throughout the entire process, a study of the complexities of school governance and of the interdependence between a school's administration and teaching staff should provide rich insights relative to the effectiveness of curriculum reform currently underway at Greenbrier Christian Academy.

As previously noted the governance model for the schooling system in America sprouted from the seedlings of a uniformed approach to education. Over the passage of time, the governance of K-12 education has gradually adopted a model of organization, leadership, and control as shaped by a variety of social, political, and economic forces. In turn the governance of education is distributed predictably among three groups filling the distinct hierarchical roles: school superintendent, principal(s), and teaching staff. At the top of the traditional governance model of education resides the school superintendent. Traditionally empowered by school boards as the educational professional, superintendents, to be successful in their role, must be the educational leaders, political statesmen, and resourceful managers (Sergiovanni, Kelleher, McCarthy, \& Wirt, 2004). However, Andero (2000) states that the role of the school superintendent within the public sector has dwelt in a state of fluctuation due to shifts in power wherein curriculum decisions are increasingly being set by court, state and federal regulations (p. 278). Sergiovanni, Kelleher, McCarthy, and Wirt (2004) confirm that "superintendents now function in a school world in which power has fractured and divided among the various 
participants in the school enterprise" (p. 213) in part due to a shift in belief about who can access, interpret, and apply both general knowledge and educational practice.

Within the hierarchical organization of the school system, the principal serves as the supportive middle manager typically tasked with instructional leadership. Throughout the evolution of this role, principals bear the weight of not only instructional leadership but also curriculum supervision, student achievement, and teacher collaboration (Sergiovanni, Kelleher, McCarthy, \& Wirt, 2004, p. 191-192). While the responsibilities of a principal currently encompass a great deal of managerial work, the individual within that role maintains a dynamic hold on the shaping and implementation of curriculum (Andero, 2000). According to Sergiovanni, Kelleher, McCarthy, and Wirt (2004) the effective twenty-first century principal will not only be an educational leader but also an organizational culture expert who can foster a collaborative spirit among a diverse grouping of individuals.

The final group to be addressed within the traditional structure of school governance holds the distinct responsibilities of both transmitting knowledge and inspiring change in others. In the traditional, bureaucratic model of school governance, teachers hold the responsibility of engaging the students using the curriculum. Ultimately, the work of presenting the content knowledge and the presentation thereof falls to the professionals within this group. The calls for decentralization and collaboration within the governance of education have been viewed as targeted efforts in returning the power of curricular decision to the teachers. Teachers represent the very individuals who invest the greatest amount of time and energies with the populations that benefit the greatest from their work (Sergiovanni, Kelleher, McCarthy, \& Wirt, 2004). Whether K-12 schools follow a traditional or contemporary view of governance, the ultimate 
success of any given reform measure is dependent upon the quality and nature of the relationship that exists between the distinct groups involved therein.

The relationship between school leadership and teaching staff has been extensively explored in books, essays, and research by Robert Evans, Ed.D., a clinical and organizational psychologist who has served as both an educator and a consultant to educators. In his article “Getting Real about Leadership,” Evans (1995) paints a picture of reform-weary leaders and skeptical teachers who need perspective, focus, and recalibration throughout relentless reforms. Evans provides two logical fallacies faced by school leaders: the technical fallacy and the corporate fallacy. The technical fallacy espouses that given enough technical training an administrative staff should easily be capable of implementing any reform measure. However, Evans points out that dependency on the latest techniques and training seminars does not fully equip school leadership to efficiently manage the intricacies of relational behaviors that naturally exist between school leadership and teaching personnel (para. 8). The corporate fallacy encourages school administrators to view the management of a school utilizing the lenses of proven business management principles. Evans defines such application of business principles as misguided - failing to recognize the unique characteristics of the education system (para. 7). Evans continues to touch on both fallacies throughout additional writings on reform and the individuals responsible for reform implementation.

In his article “Why a School Doesn't Run - or Change - Like a Business,” Evans (2000) again addresses the corporate fallacy specifically applied to reform efforts within the walls of a school. Examining key facets of school culture, Evans distinguishes educational governance and management from free enterprise-driven corporations. While Evans concedes that "a school 
must be sufficiently businesslike to survive" (What Makes Schools Unique section, para. 3), he quickly qualifies that the school is more like a non-profit service organization. As such, the individuals involved with the work of the school exhibit behavior norms which are indicative of family or church units: nurturing, instructing, and counseling. To this end, Evans points out that the operations of a school become personalized by the teachers who spend the majority of their day caring out the mission of the organization isolated from their peers. Furthermore Evans says of those who enter and stay within the field of education that such individuals hold both "a strong service ethic and a desire for job security" (What Makes Schools Unique section, para. 5). As a result of these unique traits of teachers, leaders who utilize incentives to foster reform typically fail. Such failure is due in part to the truths that teachers view education as a noncompetitive, view performance measurements as unfair, and rarely view money as an incentive to champion reform in the classroom. Ultimately, Evans argues that when administration does attempt to implement reforms leaders should seek to clearly define the forthcoming changes while highlighting the connection between the old and the new so as to provide meaningful value to the reform efforts (Fostering Constructive Change section, para. 6-8).

In both his article "The Human Face of Reform” (1993) and his book The Human Side of School Change (2001), Evans provides leaders in education an opportunity to better view both the impact that reform holds on those involved and the dynamic connection between administrators and faculty. According to Evans those who undergo change face a range of emotions from hope for growth to fear of competency, conflict, or continuity. Thus, administrators should expect both resistance and grief from the staff who they are seeking to motivate. Evans (1993) poignantly points out that "staff members' response to reform depends 
not just on its substance, but on their own readiness for change" (p. 20). The integrity and educational savvy of authentic leaders who initiate and lead reform dramatically impact the readiness levels of those who will be implementing the mandated reforms (Evans, 2001).

As individuals who are authentic in their leadership styles hold sway over the efforts of reform, Evans (2001) offers administrators biases for action which assist in inspiring teachers who want to follow them into the efforts of reform. The first bias for action, clarity and focus, is exhibited when authentic leaders limit the scope of reform efforts to a few (ideally one), clearly articulated measures or goals. Evans describes such bias in administrators as knowing what is desired, and the pursuit thereof (p. 206). To this end administrators need to be clear about both the vision for change and the connection to the foundational principles guiding the proposed or needed changes (p. 220).

The second bias for action by administration during reform is that of participation without paralysis. Evans argues that authentic leaders utilize teachers during the process of reform in a manner that is more collaborative in nature while maintaining a readiness to assert authority when such is needed. In this Evans acknowledges the complexity of shared leadership and offers a few pathways to achieving the right balance between collaboration and cooperation. The first pathway to optimal participation is clarity about decision making. In this the leader openly defines who ultimately makes which decision and how that decision is made (p. 246). The second pathway is maintaining an informal connection wherein leaders are "actively available and respectfully attentive to teachers" (p. 247). Next Evans suggests that leaders empower individuals around them to assist in the efforts of reform (p. 248). Authentic leaders must also be open to an evolution of their original reform design in order to foster the sense of 
teacher's worth throughout the collaboration (p. 249). Finally, Evans suggests that leaders must view conflict not only as an inevitable part of reform but also an opportunity for both personal and organizational growth (p. 249-251).

In line with an appropriate view of conflict, Evans identifies the final bias for action as a propensity to confront resistance as opposed to avoidance thereof. Evans clarifies that though leaders face a range of resistance inherent within the process of change, some individuals embody exceptional resistance as exhibited by behaviors that range from defiant opposition to selfish laziness (p. 273-274). To compound the issue of resistance to change, Evans proposes that the same attributes and values which draw individuals into the field of education - a spirit of nurturing and reflection - often restrict the method by which administrators confront resistance. Whether the resistance is exceptional or marginal in nature, resistance does indicate a need for clarification by the authentic leader (p. 278). As such administrators benefit from identifying the type of resistance being encountered and the best method by which such resistance should be addressed. While Evans covers both the identification and methodology within his text, the underlying principles - of clarity and connection - resound for authentic leaders looking to confront verse avoid resistance to change.

Ultimately, the success of any given reform measure will depend on the dynamic connection between the leadership and the teaching staff of a school. Such interdependent relationships are intricately complex varying dynamically based upon the values and attitudes of the individuals placed within each of those roles. The dynamics of human response to reform efforts demand that leaders understand not only the implications of reform but also the personalities of the individuals charged with carrying out reform. "Real change is always 
personal ... Success will require both high strivings and realistic acceptance - and authentic leaders who keep a steady focus on the human face of reform" (Evans, 1993, p. 23).

\section{The Principal's Role in Reform}

Given the nature of continuous reform, the importance of involved leadership throughout reform efforts, and the unique characteristics of educational governance pertaining to reform, a study of the behaviors exhibited by individuals involved within the process of reform should illuminate insights relative to the nature of those enacting reform within a school. Furthermore, a study specifically centered on the role of a principal throughout the process of reform will provide the tools necessary to evaluate the initiation and implementation of reform within the walls of Greenbrier Christian Academy.

Within any given organization individuals hold key roles for the purpose of carrying out the mission of that organization. As previously identified, schools operate with a clear management structure wherein school boards empower superintendents who task principals which depend on teachers to ensure that the mission of the school is fulfilled on a yearly basis. The dynamic relationship between all parties involved in the process of fulfilling the mission ebbs and flows based on the behaviors and attitudes of the individuals who fill each of those key roles. Thus, what behaviors and attitudes are most beneficial for individuals filling each of those key roles?

Kaiser and Craig (2011) provide valuable insights relative to effective behaviors of individuals holding key roles within an organization - separating those individuals into three basic levels: executives, middle managers, and supervisors. The two researchers studied the behaviors and attitudes of individuals within an organization including: learning agility, work- 
life balance, directive leadership, empowering leadership, supportive leadership, abrasiveness, and lack of follow-through. Within their empirical research they found that the varying levels of an organization utilized the studied characteristics differently. Executives, those at the top of an organization, hold potential for greater success when they maintain a thirst for life-long learning; they empower professionals serving under them to accomplish the mission of the organization; they sacrifice personal life for the good of an organization, and they ensure follow-through of directives (p.108-109). Middle managers exhibit greater success when they demonstrate clear support for leadership in a non-abrasive manner which bridges the gap between what has been directed by executives and what must be carried out by supervisors (p. 109). Supervisors require mastery of technical skill coupled with an appropriate work-life balance which enables those individuals to effectively accomplish given tasks within a specified time frame (p.110). It is worth noting that Kaiser and Craig identified effective supervisors as individuals who find a balance between supportive leadership and abrasiveness given their interpersonal connections to others within the organization (p. 110).

Given that those individuals serving as principals bear the responsibility of enacting the reforms in a non-abrasive manner (Kaiser \& Craig, 2011), that reform implementation has a greater chance of success within a culture of trust (Louis \& Wahlstrom, 2011), and that the changes brought on by reform are frequently viewed as unnecessary shifts away from the familiar (Evans, 1993), the principal within any given school faces an enormous challenge when seeking to implement reform of any kind within the walls of a school. Virgilio and Virgilio (1984) verify such sentiment in their claim that "the success or failure in implementing [reform] falls heavily on the shoulders of the school principal" (p. 346). Within their article "The Role of 
the Principal in Curriculum Implementation," Virgilio and Virgilio identify and address key points relative to the process of implementing a new curriculum within a school including communication, staff development, and change.

Throughout the reform implementation process, the usage of communication by the individuals involved becomes a key aspect to the success of the reform efforts (Patterson \& Czajkowski, 1979; Evans, 2005; Kaiser \& Craig, 2011; Virgilio \& Virgilio, 1984). Specifically, the type of communication and the frequency of communication hold great impact on reform efforts. Virgilio and Virgilio (1984) identify that "the principal must be a believer in open communication" wherein the following elements are either provided to or acknowledged of participating faculty members (p. 348). First, the principal must seek to provide appropriate supports to faculty members throughout the reform process. Such supports may be either in the form of available resources which support faculty efforts during reform or in the form of personal assistance as provided by the principal. Second, the principal must hold to a belief that the faculty provides valuable insights to the reform efforts as framed by the teacher's own abilities and values (p. 348). Thus the principal's role in reform, as verified by the research of Kaiser and Craig, must be that of a peace maker and translator. As such the reforms mandated by the superintendent are faithfully implemented in a manner that encourages and supports the teaching staff tasked with the labors of reform efforts.

Virgilio and Virgilio (1984) identify staff development as another key aspect within the process of reform implementation. The two researchers note that all too often administrators fail to provide adequate staff development opportunities to the individuals who bear the load of implementing reform (p. 348). Citing Patterson and Czajkowski's (1979) research pertaining to 
staff development, Virgilio and Virgilio reiterate the need to provide teaching staff with reeducation and resocialization. According to Patterson and Czajkowski's (1979) research, reeducation involves training opportunities for teaching staff with the specific objective of introducing or bolstering an individual's understanding and competency for the mandated reforms. Such re-education might be accomplished through traditional training sessions or through collaborative exchanges of peers. Resocialization involves altering or shaping personnel's “interactive skills, attitudes, and habits" (p. 206). Patterson and Czajkowski identify that resocialization represents, at best, a difficult, if not, impossible challenge during reform implementation. Thus, principals face a distinct challenge to provide not only training but also cultural direction as the teaching staff undergoes a reform of attitudes and behaviors.

Finally, Virgilio and Virgilio (1984) address the concept of change which inevitably occurs during any reform implementation. "Change is a complicated process demanding well thought-out strategies needed to accomplish new curriculum ideas" (p. 347). Additionally, change, as previously identified, involves several parties working together during which the principal must

"understand that schools committed to the long-term implementation of effective practices must be collaborative enterprises, for improvement cannot depend on any single person. [Principals must] also recognize that improving schools is a long-term proposition. New structures, programs, and practices, to endure, must become integral to the school culture" (National Middle School Association, 2010, p. 31)

Ultimately, reform is dependent upon the individuals tasked with bringing about the correlating changes of reform. Thus, Virgilio and Virgilio advocate that principals should adopt the guiding 
principles found in a model of change developed at the University of Texas entitled the Concerns-Based Adoption Model.

The Concerns-Based Adoption Model (CBAM) provides users with a conceptual framework and guidelines to be applied during the reform process. Based on a number of assumptions, CBAM postulates that individuals who are involved in the process of change ultimately experience personalized evolutions of change. Such change is evidenced by the kinds of questions those individuals ask and the degree of usage relative to the item or concept at the center of reform. The basic assumptions attributed to CBAM provide valuable insight to administrative members seeking to implement reform within the walls of a school. The first assumption of CBAM is that reform within an institution requires sufficient time as change should be viewed as a process spanning multiple years. The second assumption of the model is that change is dynamically linked to the individual changes that must occur within those who are responsible for carrying out the specific reforms of the organization. Thus, in order for a school to implement reform, administration must allow for teaching staff to process and exhibit change in a personal manner. As was just alluded to, the third and four assumptions indicate that change is a personal experience which occurs in fluctuating stages dependent upon the emotional and intellectual readiness of the individual for the stated changes. The final assumptions of CBAM indicate that administrators should continually evaluate the progress of change not only in the prescribed reform efforts but also in the individuals implementing those reforms (Asghari, Shahvarani, \& Madghalchi, 2011). Thus, principals overseeing reform should be as interested in the progress of personnel reform as they are in the progress of intended institutional reforms. 
Truly, principals do serve as the cultural leaders of their schools in that they must serve as the great communicator between members of administration and teaching staff. They must provide re-education and resocialization of teaching staff. Also, they must plan for, manage, and monitor the changes which occur as a result of reform the implementation process. In their article "Principals as Cultural Leaders," Louis and Wahlstrom (2011) offer those serving as principals four suggestions to foster both their relationships with the teaching staff and the factor of trust needed during the reform process. The first suggestion is that principals seek to preserve that which has been perceived as valuable by those tasked with reform efforts. Second, principals need to intentionally strive to alleviate or remove cultural barriers to reform. The third suggestion is that principals clearly communicate the need for and the future with the reform measures at hand. Finally, principals should continually monitor the progress throughout the implementation process (p. 56). Such suggestions align with the framework established in the Concerns-Based Assessment Model for change and establish a firm foundation upon which the principal of a school might best serve both the superintendent who is pushing for reform and the teachers who are undergoing both personal and professional reform during the implementation process. 


\section{Chapter 3: Methodology}

The case study of curricular reform measures implemented at Greenbrier Christian Academy has been built upon the interpretation of open-ended survey results, analysis of curriculum documentation, and reflection upon both the efforts to implement curriculum reform measures at the school and the research literature relevant to reform within the any given educational setting. The research study sought to answer two key questions of on-going curricular reform at the school: 1) Are the teachers seeking to improve the curriculum to which they have been entrusted? 2) Have their attitudes and perceptions regarding the change in template evolved over time? In order to answer the stated key questions, participants involved in the reform measures completed two surveys (Appendices C and D) which were coded based upon criteria established within the Concerns-Based Adoption Model. Specifically the surveys were analyzed based upon the characteristic features identified by the Stages of Concern (Figure 1) and Levels of Use (Figure 2) as summarized by Roach, Kratochwill, \& Frank (2009). Ultimately the surveys provided the researcher with both broad and isolated views of the participants' attitudes and perceptions concerning the reform.

\section{Participants of the Study}

The sixteen final participants in this case study were utilized because of their tenure in the upper school of Greenbrier Christian Academy, their work with the curricular reform measure since the initial year of the pilot study in the fall of 2011, and their willingness to participate in the follow-up teacher survey conducted in January of 2014. The sixteen final participants represented a total of 180 years of experience in the field of education (an average of 11.25 years per participant) and just over an average of eight years teaching experience per 
participant at Greenbrier Christian Academy. The range of classroom experience by the participant pool spanned decades as Anne Marie represented twenty-seven years of teaching experience and Todd represented three years of teaching experience during the 2013-2014 school year. The final sixteen participants were comprised of four males and twelve females all teaching on the upper school level.

The total potential participant pool stood at nineteen participants at the beginning of the 2013-2014 school year; however three individuals did not complete the follow-up teacher survey in January of 2014. While comments made by the individuals may be included from their initial survey when examining the Stages of Concern, information pertaining to these individuals' Level of Use and evolution of attitude could not be verified due to their non-participation. Cathy, a twenty year veteran who served in the Math Department of Greenbrier Christian Academy, was granted a new body in Heaven during March of 2014. An initial opponent to the reform measure, her insights on reform were lost as she spent the last several months of her life battling the cancer within her body. Cheryl, a long-term employee of the school, serves the school on a part-time basis and did not select to participate in the follow-up teacher survey. Kay, who has served at the school under the direction of the researcher for seven years, selected not to participate due to stated fears "that she would negatively impact the thesis work because of her opinion of the reform." Kay opposed the implementation of the reform measure both vocally and in a passive-aggressive manner as demonstrated by her minimal usage of the device during the first year of implementation. 


\section{Research Procedure}

Using a mixed methodology approach, this case study research blended analysis of a prestudy survey device (Appendix C) with a post-study survey (Appendix D). The post-study survey was created for the purposes of confirming sentiments previously expressed on the prestudy survey, of identifying the evolution of attitudes, and of confirming the perceived level of engagement between the teachers and the reform device. All participants were required to have completed the 2011 teacher survey and have remained in the employment of the school as an upper school instructor throughout the course of the past three years. As previously noted, participation in the 2014 survey was optional for participants. The 2014 survey was emailed to participants with a personal request identifying the purpose of the survey as gathering information in order to assess the curricular reform efforts in conjunction with the researcher's thesis project. In some cases the researcher made hard copies of the survey and hand delivered the paper copy to the participant with a secondary, personal plea to assist in his thesis work.

Because the 2011 survey instrument was created prior to the development of the research project, several of the prompts did not provide the researcher with pertinent information relative to the research project. However, the open-ended responses from questions nine and ten provided enough content and context for the coding of responses based on the Stages of Concern. Additionally, question nine provided a measurable response to the participants' support for the pending curricular reform.

The 2014 follow-up survey instrument was created with the intent to collect background information on each participant and to gain perspective information on the participants' current impressions, attitudes, and usages of the reform instrument. Questions five, seven, nine, and ten 
held the most value for the researcher's efforts to formulate answers to the key questions of this research project. Question seven provided measurable data relative to the evolution of the participants' attitudes toward the curricular reform. Questions five, nine, and ten were coded using the Levels of Use established in the Concerns-Based Adoption Model.

\section{Limitations of the Study}

Due to the nature of case study research, conclusions derived from the study primarily are isolated to the participating school. One of the driving principles governing qualitative research is an attempt to understand the culture in which one lives. Thus, the limited application for conclusions is appropriate and expected for this case study (Johnson \& Christensen, 2008). While one might extract the universal principles of reform highlighted by this case study, the application of those principles to any given reform effort is going to vary greatly depending on the leadership of the school, the resources available to those implementing reform, and the consistency of practice (Sindelar, Shearer, Yendol-Hoppy, \& Liebert, 2006).

One of the primary factors limiting the validity of this study remains the small sample size. Participants had to be current employees of the school who had to have been employed at the school over the course of the three year period during which curricular reform was piloted and implement. Therefore the available pool of participants was limited to a maximum of nineteen individuals at the beginning of the 2013-2014 school year. This available pool of participants would shrink to eighteen by the conclusion of the school year. Ultimately, only sixteen individuals could be included in the final survey data.

Another major limitation to the validity of the survey results could be attributed to bias within the research. As the researcher represents both an employee of the school and a member 
of the administration, the possibility for researcher bias does exist. Additionally, as the researcher initiated the reform within the school, it could be conceived that the research might filter the statements and comments provided by the participants in a biased manner. To this end the researcher attempted to limit such bias in several ways. First, when coding the surveys the researcher attempted to code statements without knowledge of the statements' owner (i.e. coding answers located on the back of the surveys first whereon participants' names were absent). Second, the researcher attempted to validate his coding of teacher comments by seeking agreement of attributed coding via an independent source. In so doing the researcher and the independent source demonstrated a 92 percent agreement of coding attributed to the participants' comments. Third, the researcher attempted to eliminate bias in analysis of the coded comments by quantifying certain aspects of the study. In turn the quantified data served as a guide for the researcher's interpretation of participants' statements and comments. Finally, the researcher sought to openly demonstrate the coding of statements and comments by including each code attributed to the cited statements within his discussion of results.

However, bias attributed to the researcher is not the only potential limiting bias of this case study. Because participants were asked to identify themselves on both of the survey instruments and because the researcher held an administrative position over the participants, this research study held the potential for participant bias as well. Such potential for bias was highlighted by Kay's refusal to participate in the follow-up survey. Thus since participants knew that the researcher would be analyzing stated views regarding the reforms initiated by the researcher, the validity of participants' claims could be called into question. This weakness, if the study were replicated, could be alleviated by using anonymous survey instruments or giving 
participants the impression thereof. However, this limitation of participant bias greatly restricts the application of results to the participating institution. Ultimately for the institution, the genuineness of participant sentiments falls to a matter of faith in the integrity of the participants.

One should note that the researcher did attempt to validate participants' claims by either duplicating prompts (i.e. - question nine from the 2011 survey and questions four and six from the 2014 survey) and cross-referencing documentation (i.e. - comparing and contrasting unit plan documents created during both the first and second year of implementation with answers to question nine on the 2014 survey). While such does not completely address the limitation posed by participant bias, such efforts do demonstrate the attempt to validate the results for Greenbrier Christian Academy.

\section{Analysis of the Study}

The researcher used a mixed-method approach to analyze and report on the findings within this research study. The researcher depended on the usage of grounded-theory methodology when performing the back and forth writing and analysis. The usage of the grounded theory was deemed necessary by the researcher because it provided the proper insight relative to the questions about the process of curricular reform at the school. Therefore, as qualitative research is rooted in the desire to assist in the understanding of one's culture, this study represents a case study providing information on the cultural impact of reform efforts at Greenbrier Christian Academy.

The analysis of the study stems from Glaser and Strauss's grounded theory methodology wherein the researcher uses initial data as a tool to generate a theory which is then further clarified or validated through additional data. The analysis of data within the grounded-theory 
approach occurs through the usage of the constant comparative method wherein the researcher consistently consults data and the developing theory. Stages of data coding and reflection occur throughout the process of analysis until the researcher reaches a point of theoretical saturation (Johnson \& Christensen, 2008). Specifically for this case study, the researcher began the study with a general knowledge of the participants' attitudes and required usage of the Unit Plan Template and steadily moved to a point of theoretical saturation following the stages of coding prescribed in the grounded-theory approach.

At the outset of the research study, the researcher had a close working knowledge of the participants' initial views on the curriculum reform instrument due to both his previous analysis of the 2011 survey. Furthermore, his work to implement the curriculum reform at the school added to the researcher's understandings prior to the research study. However, the knowledge of the participants' attitudes and perceptions were validated by the researcher's coding of the prestudy survey results using the Stages of Concern. Coding of the participants' comments was verified by Dr. Sam Botta, Head of School for Lancaster County Christian School, who acted as an independent research source. Agreement of comment coding stood at 92 percent. Following coding of each of the participants' surveys, the researcher then quantified the data by recording the number of codes attributed to each of the stages of concern per participant in a spread sheet. Furthermore, participants were categorized (based upon their response regarding future usage of the unit plan) as either supporting or opposing the reform measures. The quantified data provided the researcher with two specific categories by which the data could be further analyzed: position (support or opposition to the reform) and types of concern. The researcher reviewed each of the surveys pulling comments which reflected the stages of concern with the highest 
percentage of overall comments. During this process of extracting participant comments, the researcher began organizing the comments under common themes or concepts. Once dominant themes emerged from the axial coding of the survey, the researcher looked for connection between those themes prevalent in the research study and core concepts previously documented in published literature on educational reform.

The 2014 teacher survey was created following extensive literary research on educational reform. As previously mentioned the survey was given to the participants in January of 2014 . Analysis of the second survey did not occur until all surveys had been completed by each of the participants. Analysis of the second survey followed much the same method for verification and analysis as was conducted for the first survey. All surveys were coded and validated using the Levels of Use; the data was then quantified in a separate spreadsheet in a similar fashion to the method used during the analysis of the 2011 survey. Participants were categorized based on their response to perceived evolution of attitude and their initial position relative to the curricular reform.

The researcher then used the quantified data to further analyze the surveys for general themes based upon the participants' claim to evolution of attitude and degree of engagement with the reformed device. Furthermore, to validate or clarify claims made by participants regarding their usage of the Unit Plan Template, the researcher performed a cross comparison of submitted unit plan documents created during the first two years of reform implementation. Within the researcher's data analysis spreadsheet, the researcher recorded notes regarding the comparison and contrast of documentation as well as a generalized characterization of the degree of engagement observed during the second year of implementation. The engagement was 
characterized as either apparent, some, or little. As done during analysis of the first survey, the researcher began amassing and categorizing comments which best demonstrated or repeated the identified general themes. Finally, as the themes rose to prominence, the research again sought theoretical connection between the prevalent themes of the research study and the concepts previously espoused in the literature on educational reform.

It should be noted that the method described for the analysis of each of the surveys overlapped during the process of analysis. While the open coding of each survey occurred months apart, the selective coding of the survey data occurred simultaneously. In so doing the researcher was better able to maintain a holistic understanding of the correlating themes which existed between not only each of the surveys but also the collective themes of both surveys and the conceptual themes derived from the literature on education reforms. Therefore, the results produced and the discussion of theory flowing from the results stem from a common analysis of the two separate survey instruments.

\section{Summary}

This research study utilized a grounded theory approach. Such an approach afforded the researcher the opportunity to understand both the cultural perspectives of localized reform efforts and the perceived connections between the participants' experience with reform and literature pertaining to reform. The researcher sought the answers to culturally specific questions about the participants' engagement with the unit plan and the evolution of attitude towards the unit plan. Answers to those localized questions held broader adaptations to principles of reform previously outlined in educational reform literature. 
Participants completed two surveys conducted approximately two years apart. The researcher coded the surveys using criteria from the Stages of Concern and the Levels of Use established in the Concerns- Based Adaptation Model. Coding of comments was verified by an independent source. Coded responses were quantified in order to assist in the isolation of common themes among participant responses. Comments central to the common themes were extracted for further reflection and analysis relative to literature on curricular reform previously published.

The findings of this case study are limited to the culture of Greenbrier Christian Academy. The small sample size of sixteen final participants falls below professionally accepted norms for sample ratio. The presence for research bias existed both within the researcher's analysis and the participants responses. The researcher took measures to restrict the amount of researcher bias by utilizing a measure of blinded coding of participants' surveys, pre-establish criteria for coding, validation of coding via an independent source, and quantitative verification of common themes and/or concepts. The full potential for participant bias was not considered until the conclusion of participants' involvement with the research project. The researcher attempted to validate participants' views by the usage of duplicate survey prompts and cross referencing of documentation.

The findings of this case study provide administration with a snapshot of the evolution of attitude among teachers who were involved in the process of curricular reform. Furthermore, the study identifies a few specific areas of the reform measure which could be further clarified or could be examined for improved functionality. Using the case study on reform at Greenbrier Christian Academy, a few principles of reform connect the findings of this case study to 
literature previously published on educational reform. Thus the findings of this case study bear witness to the validity of previous research about reform in the realm of education. 


\section{Chapter 4: Results}

Using the Concerns-Based Adoption Model, coding of nineteen participants’ 2011

Teacher Survey Instrument (appendix C) yielded a total of 100 comments evidencing a range of levels within the Stages of Concern. Of the six Stages Of Concern, the participants' comments primarily fell within three of the six Stages Of Concern equaling 86 the total 100 comments: Personal (Stage 2), Management (Stage 3), and Consequence (Stage 4). Additionally support for the potential implementation of the reform measure was primarily split with 53 percent of the nineteen participants supporting and 47 percent of the nineteen participants opposing the curriculum reform measure at the time of the first survey.

Christina, an eleven year employee of Greenbrier Christian Academy, summarized her perception of the proposed curriculum reform: "The unit plan development is very time consuming [Management] but it forces you to think through all aspects of the unit which helps focus the instruction [Consequences]. However, it is hard to be motivated to invest all the time necessary to develop unit plans for the entire course content if you do not know if you will be teaching the same course the next year [Personal]." Christina's statement typifies the nature and types of comments provided by the participants during the initial teacher survey. Furthermore, Christina's statement provides the reader with an example of the researcher's coding system based on the Concerns-Based Adoption Model. Christina's statement demonstrates that certain clauses may be coded as two separate Stages of Concern represented in the same sentence. As such the examples of comments provided by participants include the assigned Stage of Concern within brackets and italicized for ease of identification. 
Management (Stage 3) and Consequence (Stage 4) represent 42 percent of the 86 coded teacher comments attributed to the three highest categories of concern. Harold, who supported the curriculum reform measure, exemplified both Stages of Concern when he wrote "[I] Think it requires a little more work upfront [Management] but leads to a better and more logically constructed flow than doing weekly plans [Consequences]." Anne Marie echoed the perceived advantage of the unit plan by stating "It offers more of a complete picture of where the unit will go [Consequence]." However, almost half of the participants did not have a favorable view of the then proposed curriculum reform measure. Janet qualified her lack of support for the proposed implementation of the unit plan in her statement, "While it was nice having my plans done for more than one week at a time [Personal/Consequence], the time required to complete it and the non-user friendly format cause me to not want to use it [Management]."

Undeniably the majority of statements provided by the participants were laced with comments which were categorized as Personal (Stage 2). Comments coded as Personal represented 50 percent of the total 100 comments and 58 percent of the three most frequently coded Stages of Concern. Kay, who vocally opposed the reform measure, stated "It takes a very long time to go through and write the unit plan [Management]. I think teachers do this type of time investment as new teachers or when they have been given new textbooks [Personal]." Kay's sentiments were echoed by fellow participant Rebecca who stated, "Since I have taught these lessons many times I did not find this format all that helpful [Personal]. I felt like I was wasting time reinventing the wheel [Management]. I was just taking what I had already done in my weekly lesson plans and transferring it to the Unit plan." Cheryl summarizes such opposition 
to the reform measure in her statement "This was very time consuming [Management] with little benefit as far as I'm concerned. The weekly plan makes more sense to me [Personal]."

Many of the statements categorized as Personal (Stage 2) hinted at a preference for format closely associated to the lesson plan template that the teachers were, at that time, using on a weekly basis. While categorized as a Refocusing (Stage 6) comment, Robin's suggested alteration to the proposed unit plan alluded to sentiments held by several of the participants: "Perhaps we could create a hybrid in which stage 3 is our old [lesson plan] template. Then the document is thoughtful and practical [Refocusing]." Robin's attempt to preserve the familiar was echoed by co-participants. "I like being able to see a week at a time horizontally" (Kay); "I would want days 1-5 on one page" (Dawn); and "[being] able to view a week [at] a time in normal lesson plan format would be beneficial." (Janet). Thus the participants' desire to retain the familiar was evident.

Other statements revealed that additional training might be necessary for effective implementation of the curriculum reform. Dawn's statement, "I felt like I kept repeating things over in stage $1 \& 2$ [Personal]", demonstrated a need for clarification of specific sections of the proposed reform tool. Dawn's sentiment was echoed by many of her fellow participants: "I felt I was very repetitive when using the unit lesson plan [Personal]" (Debby); "I felt the evidence and learning sections were redundant [Personal]" (Pamela); and "eliminate or further clarify "stage 2' [Refocusing]"' (Carlton). Certain participants' statements revealed a need for either training or experimentation with the reform tool and the application thereof. Denise demonstrated the need for training or experimentation when she stated, "The only downfall is when I have to readjust a week because of not getting to the point that I thought I would be [Personal].” Miriam's 
statement also hints at a need for continued training and exposure as she stated, "I do not know that I would specifically use Stage 3 for several reasons [Personal]. I have [students] that are doing the same type of work, but they are not usually doing the same thing at the same time. Every day requires differentiation on my part for my [students] and their individual projects. Some of them require a great deal of time be spent with them one-on-one and some are very good at working independently [Consequence/Personal]." Therefore clarification of the device was evident.

Analysis of the participants' initial survey revealed a population of teachers equally split on the proposed reform measures. Approximately half of the teachers opposed the implementation of the Unit Plan Template despite admitting to the educational merits of the researched practice. Rebecca, a 30 year veteran in the field of education, summed her opposition by stating "If I had never taught these lessons I could see how a Unit plan would be beneficial in that I would have a better idea of the big picture [Personal]." Those who supported the proposed reform measures also cited the benefit of the proposed Unit Plan Template as exemplified by Louise's statement "This is a totally different type of plan than what I'm used to [Personal], but I like that if forced me to look at the entire unit and piece it together like a puzzle, so I went into the classroom with the big picture [Consequence]." Thus administration was left with the task of deciding whether or not the perceived benefit to implementing the reform measures outweighed the personal preferences and objections of nearly half of the upper school teaching faculty.

Ultimately, the administration decided to require the upper school teaching staff to implement the Unit Plan Template as the standard document by which the teachers would access curriculum and record the planning of course instruction. The announcement of the curricular 
reform was delivered to the upper school teaching staff at the conclusion of the 2011-2012 school year in order to afford the instructional staff the opportunity to begin working on the new template over the course of the summer break. Seven faculty members did not return to an instructional position for the 2012-2013 school year. Of the seven non-returning instructors, one specifically left her position at the school due her opposition of the announced curricular reform.

Coding of the participants' responses on the 2014 Teacher Follow-up Survey (see Appendix D) yielded 59 total comments from four prompts designated to analyze the participant's perceived engagement with the unit plan following a year and a half of required usage. Of the nineteen potential participants, individuals who were participants in the 2011 Teacher Survey, only 16 participated in the follow-up survey. Of the three individuals who did not participate, Cathy lost her battle with cancer during the course of the 2013-2014 school year; Cheryl (who teaches one course during the day) never responded to participation requests; and Kay refused participation citing "I do not want my opinion of the [reform measure] to negatively impact your grade."

The participants' statements were coded using the Levels of Use as detailed in the Concern-Based Adoption Model. Mechanical Use (level 3), Routine Use (level 4a), and Refinement (level 4b) represented 71 percent of the total 59 coded comments. Routine Use represented the largest majority (39 percent) of comments submitted by the sixteen participants. When the tally of comments representing Routine Use (level 4a) is combined with comments representing Refinement (level 4b), the percentage of representation for level 4 rises to 51 percent of the total 59 coded comments. 
In some cases, the participant's comments revealed the engagement with the Unit Plan Template was limited but routine. Pamela, a supporter of the reform measure, demonstrated her level of engagement with the curriculum in her statement "once submitted, I only reference the unit plan to see what the plan for the week is [Routine Use]." Christina, an initial supporter of the reform, admits "My current usage is very minimal. I have a tendency to hand write my plans and then add them to Stage 3 when time permits [Routine Use]." Christian's level of engagement with the curriculum tool is verified by a quick comparison of the drafted versions of the unit plans submitted during the 2012-2013 school year and her unit plans submitted during the 2013-2014 school year. When analyzing the two documents side by side, one sees that the participant inconsistently updated the plans from the year previous. When updating did occur, the updates primarily occurred within the third stage of the Unit Plan Template - as should be expected of routine usage of the document.

Several of the participants provided statements that individually characterized their level of engagement as minimal however qualifying statements revealed a higher engagement level. For example Dawn, who did not initially support the reform measure, describes her usage of the template as "daily" [Routine Use]. However, she also states that her work paid off "once it's done" thus suggesting finality with her efforts to complete the document. Yet in another statement Dawn further clarifies her ongoing work with the curriculum document when she states that she is "constantly thinking ahead of what I can add to the unit since I know what the future lessons are [Refinement]." Thus Dawn's comments collectively reveal that she views the curriculum in a dynamic way now that she can both see the whole and the details of the curriculum through the Unit Plan Template. 
Rebecca is another participant whose responses revealed both a Routine Use (level 4a) and Refinement (level 4b). Rebecca states "Since I've taught the same grade [and] subjects for many years I don't use my lesson plans for much more than to remember which power point I planned to show, or I glance over it at the beginning of the week to get materials [and] assessments ready [Routine Use]." However, Rebecca clarifies the previous statement with "I tend to make the adjustments as I go. When I see that something didn't work or needs to change, I change it right then [Refinement]." Rebecca's level of engagement with the curriculum tool is verified by a quick comparison of her drafted versions of the unit plans submitted during the 2012-2013 school year and the unit plans submitted during the 2013-2014 school year. When analyzing the two documents side by side, one sees that Rebecca decided to alter the orientation of the document (as the participants were given a choice following comments gathered during the initial survey) and increase connectivity between curriculum documentation by including key hyperlinks within the unit plan. Both Dawn and Rebecca represent participants who are highly engaged in the usage of the unit plan template for the purpose of improving their work with the students.

Mechanical Use (level 3) represented 20 percent of the total 59 comments. While the comments representing Mechanical Use are varied, the comments demonstrate areas which reveal either personal attributes of the participant or areas of the reform measures which still need administrative support. For example, Harold identifies "It's been a pain trying to stay on track and annotate changes to the plans [Mechanical Use]." When one couples this statement with an understanding that Harold failed to stay on track creating and submitting unit plans the first year of implementation, one can appropriately judge that the comment speaks more to a 
personal attribute of the participant rather than a fault of the reform measure. Such characterization of Harold's Level of Use is solidified when one considers his statement that “having last year's unit plans for Statistics [which were created by Cathy] has been a huge help since I've never taught that class before." Anne Marie, a twenty-seven year veteran in the field of education, provides an example of statements which suggest an area for continued administrative support in her comment, "I still do get confused by some of the terminology [Mechanical Use]." Finally, Keith, an initial supporter for the reform measure, expresses a frustration with the Unit Plan Template that both reveals personal attributes and potential for administrative support. Keith states "I have to scroll down every day to the weekly schedule. I rarely look at the other parts. It is much more awkward to change lesson plans when a day gets interrupted by the unexpected [Mechanical Use]." While Keith's statement is personalized and reveals a superficial usage of the tool, the comment alludes to an area for examination of potential improvement.

Other participants echo, in part, Keith's desire to reevaluate aspects of the reform measure to identify potential alterations which might improve the participant's engagement with the tool. Such comments fall into the category of Renewal (level 7) as stipulated by the Levels of Use. Christina suggested that "Stage 1 Desired Results and Stage 2 Evidence could be designated as 'Part A' and remain relatively stable year-to-year. 'Part B' would include Stage 3 Learning Experiences and Stage 4 Unit Review which would be updated on an annual basis [Renewal]." Harold states " [I wish] that there was some way to improve the formatting to make it easier to copy and paste, or other move, individual days, or small groups of days with[in] the template as we make changes (less having to retype things) [Renewal]." Janet shares the desire 
to improve the template by stating "it would be nice to be able to move specific columns in the week instead of having to change info based on date changes [Renewal]."

At the outset of the research project, the researcher asked whether or not participants' attitudes and perceptions regarding the change in template evolved over time. Thus participants were asked to identify if their personal attitudes toward the usage of unit plan template had evolved over time. Table 1 provides a visual chart of the results regarding the evolution of attitudes among the participants. Of the sixteen participants who responded to the 2014 followup survey, 81 percent identified that their attitude had evolved in some manner since using the unit plan template. Primarily, the attitudes of participants evolved in a favorable manner (62.5 percent of the sixteen participants).

Table 1

Evolution of Attitude Toward the Usage of the Unit Plan Template

\section{Type of Attitude Evolution}

Favorable Attitude

of initial ${ }^{3} 10$ supporters

of initial 9 opponents

Unfavorable Attitude

Undetermined Attitude

No Evolution of Attitude

\section{Number of \\ Participants}

10

5

5

2

1

3
Percentage of
participants

$62.5 \%$

$50 \%$

$55.6 \%$

$12.5 \%$

$6.3 \%$

$18.8 \%$

\section{Overall} Percentage $^{2}$

$52.6 \%$

$26.3 \%$

$26.3 \%$

${ }^{1}$ Specifically those who submitted a 2014 Follow-up Survey (unless otherwise noted as in categorical division: ex "of initial 10 supporters")

${ }^{2}$ Representative of the nineteen total participants

3 "Initial" refers to the position given on the 2011 Teacher Survey

Statements made by the ten participants whose attitude evolved in a favorable manner range from simplistic appreciation for the completion of the work to holistic appreciation for the educational merit of the reform. Robin, initially a strong opponent to the implementation of the 
unit plan, simply stated "My attitude is much better. Most of the work is done." Also an initial opponent to the reform, Sue writes "This year has been a much easier year in using the unit plan and not as overwhelming as it was the first year. I definitely like using this better than the old lesson plan." While relief from the labor involved in the reform process is a legitimate reason for a favorable shift in attitude among teachers, statements suggesting the participants' growth as an educators stand out in sharp contrast. Dawn, also an initial opponent, exemplifies such growth in her statement "The unit plan is a lot of work but ... it does pay off once it's done. When I am in a unit I am constantly thinking ahead of what I can add to the unit since I know what the future lessons are." Also an initial opponent to the reform, Rebecca echoes Dawn's evolution of attitude when she states "I can now see the benefit of a plan that causes one to view the unit as a whole. Now that I have the Unit plans finished, it is less time-consuming to tweak them from year to year. I love that I have a 'bigger picture' of what I am doing for several weeks."

However, two of the sixteen participants (12.5 percent) acknowledged their attitudes shifted in an unfavorable manner after interacting with the Unit Plan Template. Both of the participants initially indicated conditional support for the curricular reform. Keith, who initially believed that the reform "was perfect for the e-learning assignment I used it for," revealed that continued interaction with the unit plan clarified preconceived assumptions which he held regarding the tool. Keith states in his follow-up survey "I thought it would help me plan alternative assessments since there were boxes for that kind of [thing] in the unit plan. But it didn't. So if anything, I now think even more the unit plan is just a nuisance that makes my job less efficient." Christina initially revealed support for the reform stating "[the unit plan] 
condenses all the methodologies for the unit into one place which makes it easier to tell if you are in a teaching rut and depending on one or two methodologies for presenting and/or assessing the lessons." However, Christian's initial impression of the reform tool shifted from educational merit to personal frustrations as evidence by her statement "the Unit Plan is a cumbersome document and not easily updated."

On the 2014 follow-up survey three participants (18.8 percent of the sixteen participants) acknowledged that their attitudes towards the device had not evolved since their usage of the unit plan had increased. Two of the three participants, claiming no evolution of attitude, held favorable opinions of the unit plan following the initial 2011 survey; the third participant claimed her opinion of the unit plan template was neutral during the initial piloting of the reform measure. Due to lack of explanatory response on the form, one participant (6.3 percent of the sixteen participants) acknowledged having an evolution of attitude but the researcher was unable to determine whether or not the participant's attitude reflected a favorable or unfavorable shift in attitude. 


\section{Chapter 5: Discussion}

The efforts of the administration and upper school teaching staff at Greenbrier Christian Academy to implement curricular reform has yielded circumstantial evidence supporting the literature previously published on the topic of reform. At the outset of this research project, the administrative staff sought to answer two specific questions relative to the teaching staff's engagement with the curriculum: 1) are the teachers seeking to improve the curriculum to which they have been entrusted; and 2) have their attitudes and perceptions regarding the change in template evolved over time?

The attitudes and perceptions of the upper school teaching staff at Greenbrier Christian Academy did evolve over time. Primarily, the attitudes and perceptions of the teaching staff evolved in a favorable manner since the pilot study of the reform measure. This evolution of attitude and perception aligns with several key principles found in the literature pertaining to educational reform. Those key principles of educational reform include the principles of contradiction, resistance, and perspective.

First of all, the research study revealed evidence for the principle of contradiction. The principle of contradiction refers to points in the reform process when teachers simultaneously acknowledge the benefits or educational merit of reform while opposing the implementation thereof (Evans, 1993). Rebecca aptly demonstrated this principle in a statement from her 2011 survey "If I had never taught these lessons I could see how a Unit plan would be beneficial in that I would have a better idea of the big picture." Rebecca's follow-up survey confirms that her former belief of limited benefit had expanded to include perceived value for her own thirty year career when she stated "I can now see the benefit of a plan that causes one to view the unit as a 
whole." Thus, Rebecca's personalized resistance to the reform measure, despite her initial insight to the reform's potential merit, eventually gave way to her embracing the unit plan template as evidenced by her statement from the 2014 follow-up survey: "I love that I have a 'bigger picture' of what I am doing for several weeks.'

Janet provides another example of the principle of contradiction amidst educational reform. On her 2011 initial teacher survey, Janet states "it was nice having my plans done for more than one week at a time" yet she opposed the implementation of the reform due to the time investment and unfamiliar format. However, Janet's attitude evolved over time wherein she admits that, following the work accomplished during the first year of implementation, the unit plan is "a little less daunting" and ultimately is "a good tool" for curriculum planning. Thus, Rebecca and Janet both exemplify individuals who simultaneously recognized the benefits of reform yet initially rejected the unsolicited changes which accompanied the reform: the principle of contradiction amidst educational reform.

As alluded to in the first principle of contradiction, individuals contemplating reform must anticipate the second principle of reform: resistance to the reform measures. Robert Evans (2001), a key author on the topic of educational reform, prompts leaders to prepare themselves for resistance grounded in fears of continuity (among other reasons). Resistance, filtered through the lenses of continuity, stands out among the statements provided by teachers during the initial 2011 teacher survey. Comments such as "I'd rather just do a lesson plan" (Cheryl), "I like our current template because it reads left to right" (Kay), "I would rather use the previous template" (Debby) demonstrated the natural inclination to hold to that which was most familiar. 
Cathy, initially a vocal opponent, served as an excellent example for both resistance and evolution of attitude. While Cathy was unable to complete the 2014 survey, her conversations with the researcher throughout the process and her documented usage of the Unit Plan Template demonstrates the type of evolution of attitude confirmed by the case study. On her first survey Cathy was very brief, identifying that she did not support the use of the proposed unit plan and that while "it contains good thinking processes" she would "replace Stage 3 with weekly plans." This brief statement led to several meetings between the researcher and Cathy. As a result, the layout of the unit plan template was modified to include an optional template wherein Stage 3 appeared in a landscape format representing five days at a time. The optional landscape format provided a familiar layout to which teachers were accustomed.

The compromise of format both alludes to the third principle of reform and confirms George Friedrich Hegel's philosophy of dialectical reasoning. Dialectical reasoning suggests that conflict in reform produces a cycle of conflict until all involved in the reform efforts arrive at an agreed upon position. Thus, the third principle of perspective in reform becomes a key factor for leadership who should retain a long-term view of reform (Ediger, 1998). As described in the example with Cathy, the researcher, serving in a position of leadership, had to weigh the faculty's conflicting desires to maintain continuity with the perceived benefits of successfully implementing the reform measure. Thus, the researcher had to accept the benefit of compromise knowing that such compromise was necessary to support the ultimate goal of curriculum reform. Cathy's attitude toward the unit plan device did evolve over time. While she was not a fan of the amount of work that it took to convert from the weekly lesson plans to the Unit Plan Template, she too began acknowledging the benefit of seeing the bigger picture when planning 
units of instruction based on Wiggins and McTighe's backwards design. Statements of support were both delivered to the researcher in passing throughout the first year and to the faculty which served under her leadership as the Math Department Head. However, her shift in attitude is revealed more clearly when one considers that (following the first year's efforts to convert lesson materials to the optional Unit Plan Template with the modified Stage 3) she began her second year converting, yet again, each of her units to the originally proposed template which placed Stage 3 in a portrait format (as pictured in Appendix A). Thus, Cathy serves as a solid example of one who resisted the curricular reform and one whose attitude relative to the reform device evolved over time.

Finally, pertaining to the evolution of attitude amidst reform, individuals considering reform efforts should be well acquainted with the principle of perspective. Teachers tend to hold to a short term view of reform personalizing the impact of the reform measures within their own sphere of influence (Louis and Wahlstrom, 2011). Both the large percentage of personal comments, as coded using the Stages of Concern, and the subject matter of those comments help validate this principle. Comments by the participants continually pointed at either personal preferences or personal applications of the Unit Plan Template. Such comments include "the process takes way too long for the amount [it] will be used (which is not likely)" (Robin), "When I have the opportunity to use this plan for a unit not tied into my deadlines, I think I will like it" (Miriam), "I think weekly plans are more helpful, more detailed." (Cathy), and "Since I have taught these lessons many times I did not find this format all that helpful” (Rebecca).

Dawn exemplifies the evolution of attitude within the principle of perspective. The majority of Dawn's teaching experience can be isolated to the walls of Greenbrier Christian 
Academy. At the time of the 2011 pilot test of the unit plan, she had spent two of her five years in the field of education teaching history for the school. In 2011 she stated of the unit plan that it was "too much work" and that she preferred "to be more spontaneous in my class."

Furthermore, she stated that she too wanted "Stage 3 to be five days at a time [and she felt like she needed] to add on to in weekly." Thus, her perspective in 2011 was grounded in a format with which she was most familiar, focused on a perceived limitation of the unit plan, and opposed to the amount of effort needed to develop the unit plan.

However, Dawn's attitude and perceptions about the unit plan did evolve over the course of time. While Dawn admits in her 2014 survey that she "still believes [it is] a lot of work," Dawn demonstrates an evolution of mindset in her comment "it requires me to plan ahead which in the end I appreciate." Dawn now possess a long term view of planning her instruction which ultimately fosters her previously expressed desire to be spontaneous in class. Such a view of planning is exemplified in her statement "When I am in a unit I am constantly thinking ahead of what I can add to the unit since I know what the future lessons are.” Thus, Dawn's experience throughout the process of reform demonstrated a positive shift in her perspective not only of the unit plan but also for the freedom she possess within the curriculum to be spontaneous in a way that complements the goals and objectives of the unit.

With 81 percent of the sixteen participants' admitting to and describing various types changes relative to their usage of the Unit Plan Template, one can concede that the attitudes and perceptions have evolved among the faculty at Greenbrier Christian Academy during the course of curricular reform. However, identifying whether or not the teaching staff is working to "improve" the curriculum is a question more difficult to answer. In short the researcher can 
demonstrate that a measure of engagement between the teachers and their curriculum does exist; however that engagement does not necessarily equate to improvements within the curriculum.

Early on in the process of considering the possibility of initiating curricular reform at the school, Glenda, the school's Academic Dean, stated that "it really doesn't matter whether or not teachers use the lesson plan template or the unit plan template to record their curriculum planning, but it's how they use it." Such rings true when seeking to classify whether or not the teachers are improving the curriculum entrusted to them. One certainly can argue that the teachers have every opportunity to access, interact, and improve the curriculum following the implementation of the Unit Plan Template, wherein curriculum documentation is unified. Such unification of access stands in contrast to the separate filing of curriculum documents under the previous curriculum structure. However, improvements to the curriculum seemingly depend on each individual teacher's perspective of being a lifelong learner. To this end this historical study of curricular reform does not answer the question whether or not teachers are improving the curriculum but how they are engaging with the curriculum.

Based on data generated by the Levels of Use, comments from the teachers indicated that 37 percent of the participants indicated a type of usage that falls below the fourth Level of Use. Interestingly, the fourth Level of Use is subcategorized into Routine Use and Refinement (representing 51 percent of the teacher's comments). Routine Use (representing 39 percent of the comments) is categorized by the word "stability" wherein the individual makes few changes and gives little thought to improving their usage of the device. Contrastingly, Refinement (representing 12 percent of the comments) is categorized by efforts made to use the device for the purpose of improving some aspect of the educational environment or curriculum (Roach, 
Kratochwill, \& Frank, 2009). Thus, the difference between Routine Use and Refinement becomes a key dividing line for analyzing whether or not the teacher's engagement in deed equates to improvement.

If then the division between Routine Use and Refinement represents the division between task-oriented engagement and improvement-laden engagement, then the data reveals that 76 percent of the comments made by teachers indicate that they might perceive the device as one that is complete once the boxes have been populated. Statements provided by select teachers seem to bear out this theory of a task-centric faculty: "I have been using previous unit plans but have not updated them as often as I should" (Carlton), "Most of the work is done" (Robin), "I interacted with the unit plans more when I first worked with them. However, I do rely on them weekly to update my 'Lesson plans' and [homework]”' in the grade management system (Janet). However, the quantitative view of the teacher's usage of the Unit Plan Template is blurred by conflicting statements made by the teachers. For example, Dawn states that the reform efforts did "pay off" once the work was complete (thus suggesting Routine Use of the device) but then contradicts herself by stating "I am constantly thinking ahead of what I can add to the unit since I know what the future lessons are." Thus, Dawn exemplifies several other participants who find themselves caught in the middle between Routine Use and Refinement.

To be fair to the participants, the data gained from examining the Levels of Use must be considered with the knowledge that the intensity of work expected of the participants drastically changed between year one of implementation and year two of usage. During year one the participants were expected to complete a unit plan for each of their assigned courses (traditionally two courses, but three and four in some cases) spanning the course of the entire 
school year. Janet best captures the sentiments of her fellow participants when she states that at first she "viewed it as overwhelming and seemed [like it was] an impossible task to complete coupled with everything else I was balancing." Following the initial year of implementation the teachers are rightfully relieved to have the majority of the work accomplished. Louise states "It's nice to have them done from last year to be able to tweak and fix for this year." Therefore, as the teachers move towards their third year of usage of the Unit Plan Template, the participants' comments indicated that they are precariously poised between the subcategories of the fourth Level of Usage.

In summary this case study suggests that while the participants are engaged with the Unit Plan Template, the level of engagement is routine following the first year of implementation. Thus, the teachers are not concentrating on improving the curriculum documentation as desired by the administration. Fortunately for the administrative staff, the data reveals that the attitudes and perceptions of the participants did evolve over time primarily in a positive manner.

Participants now see the benefits of using the device. Therefore, as administration seeks to direct the teachers towards consistently improving the device, the administration should consider ways to encourage teachers to improve the device which build upon the perceived benefits of the device.

\section{Recommendations}

In light of the participants' comments regarding their engagement with the Unit Plan Template and that reform measures often fail due to leadership oversight extending beyond the initial implementation period (Ediger, 1998; and Sindelar, Shearer, Yendol-Hoppy, \& Liebert, 2006), the researcher suggests that the administration of Greenbrier Christian Academy seek 
ways to integrate curriculum-focused school improvement projects with teacher analysis of the unit planning tool. For example were assessment methodology identified as a potential weak point of teacher instruction, in-services might require teachers to not only examine assessment samples but also evaluate and clarify documentation of assessment strategies within the unit plan. If the school were to identify biblical integration as a weak point for course instruction, teachers might be required to demonstrate application of in-serviced topics related to biblical integration within their unit plan documentation as well as during classroom observations.

Because research indicates that a primary weakness of reform implementation falls to teacher turnover (Ediger, 1998) and given the percentage of turnover since the 2011 pilot of the unit plan stands at 55 percent for the upper school faculty, analysis of that population of employees would be beneficial towards sustaining the curricular reform efforts initiated in the past three years. Thus, the researcher suggests that the administration consider extending the study of engagement with the curricular device to the teaching staff who has taken a position within the upper school since the implementation of the unit planning device. The study of interactions between the newly hired employees and the device could include a look at what stages of the unit plan those employees found most helpful their first year of interaction, an evaluation of struggles they faced when using the device, and a description of how they currently engage with the unit plan. While this recommendation also falls under the category of further research, the information gained from this type of study extension should provide valuable feedback for the administration.

Finally, comments from the follow-up survey identify two areas which should be considered by administration in order to foster continued improvement and engagement with the 
unit plan. First, the researcher noted several comments identifying frustration with ease of access or ease of manipulation relative to Stage 3. As to ease of access, the researcher suggests the usage of internal "hyperlinks" or "cross-references" embedded within the first page of the electronic document. The hyperlinks would allow users to quickly advance to specified places within the document thereby alleviating some of the annoyances expressed by users who do access the document on a daily basis for the purposes of engaging with Stage 3 . In reference to ease of manipulation, the researcher suggests investigating the merger of Excel with the Word document. One of the participants had begun using Excel for Stage 3, however, in so doing, has separated the curriculum back into two separate documents. While the researcher is unfamiliar with the usage of both software programs simultaneously, the researcher does see benefit in exploring this possibility based on his understanding of Excel.

The second area, to which administration should give consideration falls to in-depth, focused training for the usage of Stage 1. Some of the participants expressed continued confusion relative to perceived redundancies within this stage. As this stage serves as the beginning point for the development of assessments and instructional methodologies, fortifying the users' understanding of each portion or category within Stage 1 should assist the teachers in better understanding the big picture provided by the unit plan. Thus, the researcher suggests that some faculty meetings for the forthcoming school year be designated towards teacher training for each of the categories found in Stage 1.

\section{Biblical Integration}

In the book of Romans, the apostle Paul charges Christians in the following manner: 
I appeal to you therefore, brothers, by the mercies of God, to present your bodies as a living sacrifice, holy and acceptable to God, which is your spiritual worship. Do not be conformed to this world, but be transformed by the renewal of your mind, that by testing you may discern what is the will of God, what is good and acceptable and perfect (Romans 12:1-2, English Standard Version).

The term transformed is derived from the Greek term metamorphoo which means a change from one state of being into another. The term renewal stems from the Greek term anakainosis which carries the meaning of "renovation" or a "complete change for the better" (Strong \& Vine, 1999). In this Paul argues that Christians, who through the blood of Christ and the power of the Holy Spirit, are to be set apart from the surrounding culture through metamorphoses. Such differentiation between the individual and the culture comes at the expense of a self-serving will. Furthermore, the metamorphosis cannot occur apart from a reformation of the mind.

As Christians we are called to exemplify a people set apart for the glory and honor of our LORD in heaven. From Genesis we know that we bear His image (Genesis 1:27). The Ten Commandments instructs us to bear His name in a manner worthy of His name (Deuteronomy 5:11, Exodus 20:7). Jesus guides us to live as salt and light in a lost and dying world (Matthew 5:13-16). Paul reminds us that, while we are fallen vessels (Romans 3:23), we are to walk in the good works that have been laid out for us (Ephesians 2:8-10). Thus, we must recognize that during our time here on this side of eternity, we are to embrace the evolution of our spiritual lives through the reformation of our minds.

Spiritual reform will occur through a multitude of methods over the course of our lives. Reform will not always look the same for each of us; yet it is necessary in each of us for our 
spiritual growth and maturity (1 Corinthians 3). However, the principles, evidenced by this study of curricular reform, ring just as true in one's spiritual walk. As the Holy Spirit initiates reform measures in the lives of His people, the principles of contradiction, resistance, and perspective will arise. In many cases promptings from the Holy Spirit to initiate reform within our spiritual walk are met with resistance and statements of rationale which contradict one another. Following the passage of time and the continued work of the Holy Spirit, our shortterm, earthly perspective evolves to an eternal gaze on the One who created us.

Often God uses the circumstances of life around us to transform our attitudes and perspectives. As Christians we should be cognizant of the truth that God calls us to be set apart as educators. We must seek an engagement with God's Word that allows for refinement of our spiritual walk verses a mere routine exposure to His Word. We are truly blessed in that the Holy Spirit leads us through the reform process in a manner that is nurturing and allows for reflection and meditation. Again reform is a difficult process; yet it is only through the process of spiritual reform that one hopes to hear the words, "Well done my good and faithful servant" (Matthew 5:14-30). James encourages Christians and refers to spiritual reform in this way:

Count it all joy, my brothers, when you meet trials of various kinds, for you know that the testing of your faith produces steadfastness. And let steadfastness have its full effect, that you may be perfect and complete, lacking in nothing. If any of you lacks wisdom, let him ask God, who gives generously to all without reproach, and it will be given him (James 1:2-5).

May each of us embrace the reform as it comes knowing "that for those who love God all things work together for good, for those who are called according to His purpose" (Romans 8:28). 


\section{Suggestions for Further Research}

As previously identified, the research study on curriculum reform could be extended to investigate the attitudes, perceptions, and engagement of individuals who have entered the process of reform midway. A research study focused on this group of individuals might provide valuable insight to the leaders of reform regarding the sustainability of reform efforts despite teacher turn over. The study could utilize the Concerns-Based Adaption Model to characterize the Stages of Concern expressed by the participants entering the reform efforts midway. Thus, the attitudes and perceptions of incoming reform participants could be measured. Additionally, the study could utilize the Levels of Use to examine the type of engagement which the incoming individual described as having with the reform measure. If time were not a factor, the study could be spread over multiple years through repeated surveys in order to determine the evolution of attitude experienced by the incoming participant.

Another avenue for further research could focus on the potential connection between participant disposition and participant engagement with curricular reform. In essence the researcher would ask the question “to what degree does a teacher's disposition to learning (lifelong learner) impact that teacher's engagement with curriculum?" While not specifically noted in the data from this case study of curriculum reform, the researcher did notice a correlation between a participant's increased interaction or engagement with the curriculum document and the participant's disposition towards learning. The thesis would be that an individual who demonstrates characteristics of a life-long learner will apply that disposition to reform efforts. Furthermore, the researcher would anticipate that such a thesis would hold true despite the individual's attitude toward any given reform measure. 
The case study of the curricular reform efforts at Greenbrier Christian Academy has provided additional data supporting previously published claims regarding educational reform. Educational reform, no matter the size or the focus, is a difficult process. Participants involved with reform measures should be cognizant of key principles of contradiction, resistance, and perspective. This research study confirms those key principles and suggests that over time the spirit of resistance will give way as the participants' perspectives evolve including and, at times, expanding the benefits once attested to during their initial resistance. 


\section{References}

Andero, A. (2000). The Changing Role of School Superintendent with Regard to Curriculum Policy and Decision Making. Education, 121(2), 276.

Asghari, N., Shahvarani, A., \& Medghalch, A. (2011). Preparing Elementary Teachers to Foster Functional Thinking. Australian Journal Of Basic \& Applied Sciences, 5(12), 485-489.

Branyon, J. B. (2012). Enacting a Common Core Curriculum: The Kenya Study. Delta Kappa Gamma Bulletin, 79(2), 40-46.

Cruz, G. (2010). A Quick Fix for Bad Schools. Time, 175(7), 85-87.

Ediger, M. (1998). Change and the School Administrator. Education, 118(4), 541.

Evans, R. (1993). The human face of reform. (Cover story). Educational Leadership, 51(1), 19.

Evans, R. (1995, April 12). Getting Real about Leadership. Education Week. p. 36.

Evans, R. (2000). Why a School Doesn't Run -- or Change -- like a Business. Independent School, 59(3), 42.

Evans, R. (2001). The Human Side of School Change: Reform, Resistance, and the Real-Life Problems of Innovation. San Francisco: Jossey-Bass.

Feldmann, D. (2005). The Committee of Ten to the Cardinal Principles, 1893-1918. Research for Educational Reform, 10(2), 41-50.

Finn Jr., Chester E. (2013). Why Private Schools Are Dying Out. The Atlantic. Retrieved from http://www.theatlantic.com/national/archive/2013/05/why-private-schools-are-dyingout/275938/

Greenbrier Christian Academy Parchments (vol. 1), (1984).

Gress, J. R. (1976). Curriculum: Variations on Themes. Theory Into Practice, 15(2), 98. 
Haft, S., Witt, P. J., \& Thomas, T. (Producers), \& Weir, P. (Director). (1989). Dead Poets Society [Motion picture]. United States: Touchstone Pictures.

Hamilton, J., Johnston, S., Marshall, J., \& Shields, C. (2006). Making the Most of Time. Educational Leadership, 63(8), 72-73.

Haywood, H. (2004). Thinking in, Around, and about the Curriculum: the Role of Cognitive Education. International Journal Of Disability, Development \& Education, 51(3), 231252. doi:10.1080/1034912042000259215

Johnson, B., \& Christensen, L. (2008). EDUCATIONAL RESEARCH: Quantitative, Qualitative, and Mixed Approaches ( $3^{\text {rd }}$ ed.). Thousand Oaks, California: Sage Publications, Inc.

Kaiser, R. B., \& Craig, S. (2011). Do the Behaviors Related to Managerial Effectiveness Really Change with Organizational Level? An Empirical Test. Psychologist-Manager Journal, 14(2), 92-119. doi:10.1080/10887156.2011.570140

Katzman, John. (2012). Putting the Schools in Charge. Education Digest, 78(4), 37-47.

Khoboli, B., \& O'toole, J. (2012). The concerns-based adoption model: Teachers' participation in action research. Systemic Practice And Action Research, 25(2), 137-148. doi:10.1007/s11213-011-9214-8

Lee, V. E., \& Ready, D. D. (2009). U.S. High School Curriculum: Three Phases of Contemporary Research and Reform. Future Of Children, 19(1), 135-156.

Lipsitz, J., West, T. (2006). What Makes a Good School? Identifying Excellent Middle Schools. Phi Delta Kappan, 88(1), 57-66.

Morrison, S., \& Sams, B. (2011). Letter from the Editorial Board. High School Journal, 94(2), 41-42. 
National Center for Education Statistics. (2013). Table 1. Actual and projected numbers for enrollment in grades $P K-12, P K-8$, and 9-12 in elementary and secondary schools, by control of school: Fall 1996 through fall 2021. Retrieved from http://nces.ed.gov/programs/projections/projections2021/tables/table_01.asp

National Center for Education Statistics. (2013). Table A-5-3. Percentage distribution of students enrolled in private elementary and secondary schools, by school type and selected characteristics: 2009-10. Retrieved from http://nces.ed.gov/programs/coe/tables/table-pri-3.asp

National Middle School Association/the Association for Middle Level Education (Eds.). (2010). This We Believe: Keys to Educating Young Adolescents. Westerville, OH: Association for Middle Level Education.

Patterson, J. L., \& Czajkowski, T. J. (1979). Implementation: Neglected Phase in Curriculum Change. Educational Leadership, 37(3), 204.

Patterson, J., \& Patterson, J. (2004). Sharing the Lead. Educational Leadership, 64(7), 74-78. Roach, A. T., Kratochwill, T. R., \& Frank, J. L. (2009). School-Based Consultants as Change Facilitators: Adaptation of the Concerns-Based Adoption Model (CBAM) to Support the Implementation of Research-Based Practices. Journal Of Educational \& Psychological Consultation, 19(4), 300-320. doi:10.1080/10474410802463304

Rust, Terrie. (2012). Common Core Standards. Technology \& Engineering Teacher. 72(3), 3236.

Sawchuk, S. (2011). School Restructures Student Grouping. (Cover story). Education Week, 30(17), 1-13. 
Seashore Louis, K., \& Wahlstrom, K. (2011). Principals as Cultural Leaders. Phi Delta Kappan, $92(5), 52-56$.

Sergiovanni, T. J., Kelleher, P., McCarthy, M. M., \& Wirt, F. M. (2004). Educational Governance and Administration (5 ${ }^{\text {th }}$ ed.). Boston: Pearson \& Allyn and Bacon.

Sindelar, P. T., Shearer, D. K., Yendol-Hoppey, D., \& Liebert, T. W. (2006). The Sustainability of Inclusive School Reform. Exceptional Children, 72(3), 317-331.

Sliwka, A., \& Istance, D. (2006). Parental and Stakeholder 'Voice' in Schools and Systems. European Journal Of Education, 41(1), 29-43. doi:10.1111/j.1465-3435.2006.00244.x

Spring, J. (2005). The American School: 1642-2004. (6 $6^{\text {th }}$ Ed.). Boston, MA: McGraw Hill.

Strong, J., \& Vine, W. E. (1999). Strong's Concise Concordance And Vine's Concise Dictionary Of The Bible: Two Bible Reference Classics In One Handy Volume. (1 ${ }^{\text {st }}$ Ed.). Thomas Nelson, Inc.

Roach, A., Kratochwill, T., \& Frank, J. (2009). School-Based Consultants as Change Facilitators: Adaptation of the Concerns-Based Adoption Model (CBAM) to Support the Implementation of Research-Based Practices. Journal of Educational and Psychological Consultation, 19, 300-320.

Ullman, E. (2012). The Perfect Blend. Technology \& Learning, 33(3), 46-48.

Virgilio, S. J., \& Virgilio, I. R. (1984). The Role of the Principal in Curriculum Implementation. Education, 104(4), 346.

Ward, J. (April 19, 2012). Selecting Your Future [Television Broadcast]. Norfolk, VA: WTKR News Channel 3.

Wiggins, G. (2011). A Diploma Worth Having. Educational Leadership, 68(6), 28-33. 
Appendix A

Greenbrier Christian Academy Unit Plan Template

\section{Cover Page}

Unit Title:

Subject/Topic Areas:

Key Words:

Designed by:

School: Greenbrier Christian Academy
Grade Levels:

Time Frame:

\section{Brief Summary of Unit:}

Biblical Integration:

Key Themes: 


\section{Stage 1 -Desired Results}

Established Goals: (as taken from the Virginia Department of Education website. Standards of Learning)

\begin{tabular}{|l|l|}
\hline What essential questions will be considered? & What understandings are desired? \\
\hline & \\
\hline
\end{tabular}

What key knowledge and skills will students acquire as a result of this unit?

Students will know ... Students will be able to ... 


\section{Stage 2 -Acceptable Evidence}

What evidence will show that students understand?

Performance Tasks:

What other evidence needs to be collected in light of Stage 1 Desired Results?

Other Evidence:

Student Self-Assessment and Reflection: 


\section{Stage 3 -Learning Experiences}

\begin{tabular}{|c|c|c|}
\hline Day One: & &, 2012 \\
\hline Homework: & Materials: & \\
\hline Day Two: & &, 2012 \\
\hline Homework: & Materials: & \\
\hline Day Three: & &, 2012 \\
\hline Homework: & Materials: & \\
\hline Day Four: & &, 2012 \\
\hline Homework: & Materials: & \\
\hline Day Five: & &, 2012 \\
\hline Homework: & Materials: & \\
\hline
\end{tabular}




\section{Stage 4 - Unit Review}

What adjustments need to be made for the next year?

Content Presentation:

Unit Pacing:

Student Assessment:

Biblical Integration:

Identify any curricular issues which need to be addressed within your department: 
Appendix B

\section{Greenbrier Christian Academy Lesson Plan Template}

Greenbrier Christian Academy 2011-2012

Course:

Instructor:
Quarter: /Week:

Unit Title:

Time Frame:

\begin{tabular}{|c|c|c|c|c|}
\hline Monday $\quad \mathrm{xx} / \mathrm{xx} / \mathrm{xx}$ & Tuesday & Wednesday $\quad x x / x x / x x$ & Thursday $\quad x x / x x / x x$ & Friday $\quad \mathrm{xx} / \mathrm{xx} / \mathrm{xx}$ \\
\hline Lesson: & Lesson: & Lesson: & Lesson: & Lesson: \\
\hline Objectives: & Objectives: & Objectives: & Objectives: & Objectives: \\
\hline Methods: & Methods: & Methods: & Methods: & Methods: \\
\hline Materials: & Materials: & Materials: & Materials: & Materials: \\
\hline Evaluation Technique: & Evaluation Technique: & Evaluation Technique: & Evaluation Technique: & $\begin{array}{l}\text { Evaluation } \\
\text { Technique: }\end{array}$ \\
\hline HW: & HW: & HW: & HW: & HW: \\
\hline \multirow{2}{*}{\multicolumn{5}{|c|}{ Biblical Integration/Application: }} \\
\hline & & & & \\
\hline \multicolumn{5}{|l|}{ SOL: } \\
\hline
\end{tabular}




\section{Appendix C \\ 2011 Teacher Survey Instrument}

\section{Unit Plan Teacher Survey}

name:

course:

for what course did you implement the unit plan

1. How much time did you spend developing your unit plan? (in minutes)
0-15
$16-30$
31-45
46-60
$61+$

What percentage of time (identified above) was invested in:

$\begin{array}{lr}\text { recording your information within the template } & \% \\ \text { learning/understand the specific format of this unit plan } & \% \\ \text { improving specific aspects of the lesson (i.e. - biblical } \\ \text { integration, objectives, assessments, and/or methodologies) }\end{array}$

2. Of the total time you spent developing your unit plan, identify the amount of time you spent on each of the sections within the unit plan:

Cover Page

Stage 1 - Desired Results

Stage 2 - Acceptable Evidence
Stage 3 - Learning

Experiences

Stage 4-Unit Review

3. How much time do you typically spend developing a weekly lesson plan document? (in minutes)

0-15

$16-30$

$31-45$

46-60

$61+$

On average, how many weeks constitute one unit of instruction in the courses that you teach?

1

2

3

4

4. Did you seek out help in order to fulfill the requirement placed on you to use this unit plan?

yes no

If yes, what method(s) did you use?

[?] Unit template with descriptors

?] Advise from a GCA

? Online research about "Backwards employee/administrative staff

Design" 
5. To what degree did you find the template challenging to use? (1 represents extremely simple to use and 10 represent extremely difficult)
1
23
34
5
6
7
8
9
10

6. To what degree do you believe this impacted your teaching practice within the classroom? (1 represents extreme negative impact within the classroom and 10 represent extreme positive impact within the classroom)
1
2
3
$4 \quad 5$
6
7
8
$9 \quad 10$

7. Of the unit plan stages identified on the

Stage 1

Results

Stage 2 Evidence

Stage 3

Stage 4

difficult to utilize within the planning process?

advantageous to the planning

process?

repetitive to the planning process?

\begin{tabular}{|l|l|l|l|}
\hline & & & \\
\hline & & & \\
\hline & & & \\
\hline
\end{tabular}

8. In developing your unit plan, did you complete the plan in the sequence laid out in the template (i.e. - you completed stage 1 , then stage 2 , followed by stage 3$)$ ?

yes no

9. Would you use this type of plan on a consistent basis? (why or why not)

yes

no

10. What alterations would you make to the template in order to better suit educational practice or to accommodate subject specific concerns?

\section{Additional Comments:}




\section{Appendix D \\ 2014 Teacher Follow-up Survey Instrument}

\section{Participant Information:}

Name

Position Held

1. For how long have you worked in the field of education?

2. For how long have you been employed by GCA?

3. Would you describe yourself as an individual who likes or embraces change in your life?

[?]

yes
?

no

\section{Questions Regarding Perspective and Attitude Relative to the Curricular Reform Efforts}

4. How would you describe your first impression of the Unit Plan Template when it was presented to the faculty in September of 2011?

5. How would you describe your current impression of the Unit Plan Template after having interacted with the tool for over a year?

6. How would you describe your attitude at the outset of the transition to the Unit Plan Template at the beginning of the 2012-2013 school year?

7. Would you say that your attitude regarding the usage of the Unit Plan Template has changed or evolved since that point in time?

$\begin{array}{cc}\text { ? } & \text { ? } \\ \text { yes no }\end{array}$

If yes, how has your attitude changed? 
to what do you attribute your change in attitude?

8. Considering the entire process of transitioning to the Unit Plan Template, what, if any, suggestions or insights might have made the process of transitioning easier for you?

9. How would you characterize/describe your current usage of the unit plan template?

10. Are there areas of the Unit Plan that you believe you still need to improve upon or address for future usage? 